\title{
Technology Integration: A Research-based Professional Development Program
}

Tori R. Faulder

Cedarville University

Follow this and additional works at: http://digitalcommons.cedarville.edu/education theses

Part of the Education Commons

\section{Recommended Citation}

Faulder, Tori R., "Technology Integration: A Research-based Professional Development Program" (2011). Master of Education Research Theses. 30.

http://digitalcommons.cedarville.edu/education_theses/30 
TECHNOLOGY INTEGRATION:

A RESEARCH-BASED PROFESSIONAL DEVELOPMENT PROGRAM

\author{
A thesis submitted in partial fulfillment \\ of the requirements for the degree of \\ Masters of Education
}

\begin{abstract}
By
TORI ROSE FAULDER

B.A. Middle Childhood Education, Mount Vernon Nazarene University, 2005
\end{abstract}

2011

Cedarville University 


\author{
CEDARVILLE UNIVERSITY
}

SCHOOL OF GRADUATE STUDIES

January 30,2011

I HEREBY RECOMMEND THAT THE THESIS PREPARED UNDER MY SUPERVISION BY Tori Rose Faulder ENTITLED Technology Integration: A Researchbased Professional Development Program BE ACCEPTED IN PARTIAL FULFILLMENT OF THE REQUIREMENTS FOR THE DEGREE OF Master of Education.

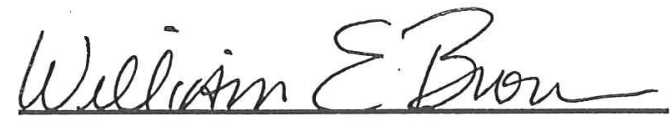

William E. Brown, Ph. D.

President

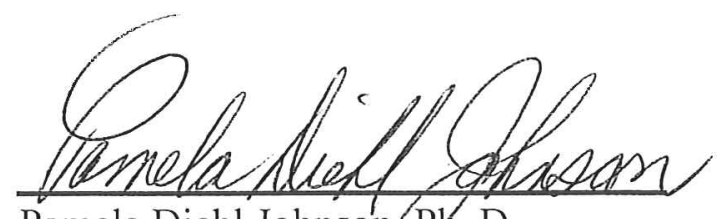

Pamela Diehl Johnson, Phr. D. Dean, School of Social Sciences and Human Performance

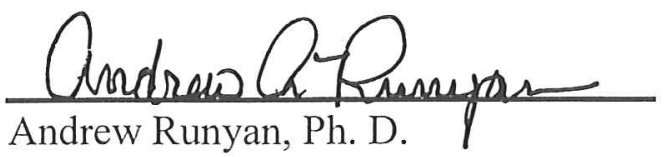

Dean, Graduate School

Associate Academic Vice President

Thesis Advisor

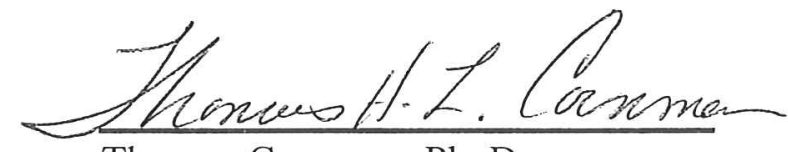

Thomas Cornman, Ph. D.

Academic Vice President
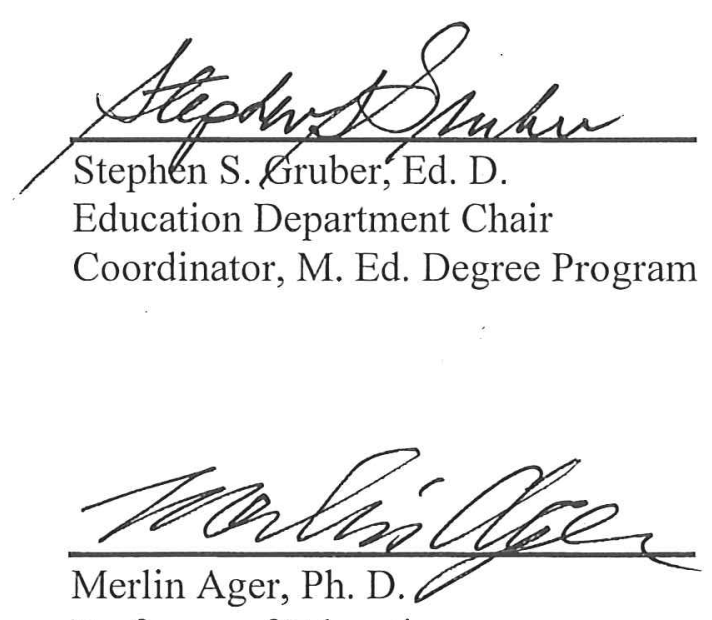

Professor of Education 


\begin{abstract}
Faulder, Tori R. M.Ed., Education Department, Cedarville University, 2011. Technology Integration: A Research-based Professional Development Program
\end{abstract}

This research-based thesis project explains the governmental acts and policies, investors, and other stakeholders who have worked to promote, question, and explore the use of information and communication technologies (ICT) in the classroom. Research suggests that best-practice ICT integration requires using ICT alongside constructivist pedagogy. However, ICT integration is a complex phenomenon involving a significant number of factors. Teachers have often taken the blame for a failure to effectively integrate ICT in their classrooms due to their integral role in effective integration. This research project attempts to ensure that teachers will be equipped, empowered, and encouraged to include ICT in their instructional repertoires through the development of a research-based professional development program. While this professional development program will only address the teacher factors involved in ICT integration, it is an essential step toward effective integration. 


\section{TABLE OF CONTENTS}

I. INTRODUCTION ......................................................

Definition of Terms...........................................................

Statement of Issue ............................................... 9

Scope of the Study and Delimitations...................................10

Significance of the Study............................................12

Methods of Procedure................................................ 14

II. PLENARY LITERATURE REVIEW ..................................

Governmental Policy and History of ICT in Education...................15

Promises of ICT Use................................................. 34

Constructivism.................................................. 43

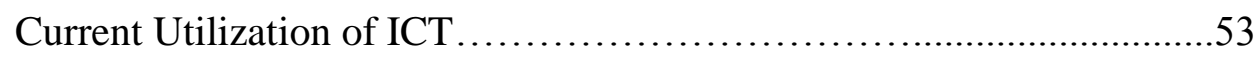

Integration...................................................... 61

Integral Role of the Teacher................................................68

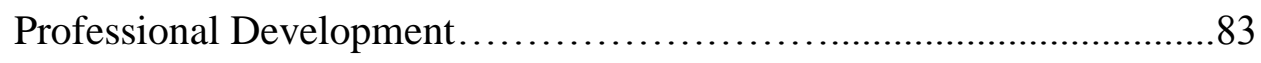

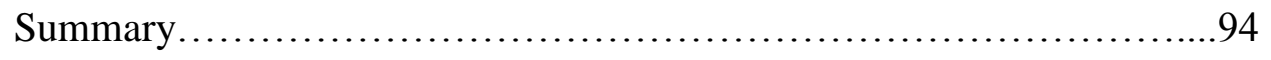


III. PROFESSIONAL DEVELOPMENT PROGRAM........................96

Phase One: School Culture.....................................96

Phase Two: Training Teacher-Mentors...........................96

Phase Three: Non- and Limited-Use Teachers......................105

Phase Four: Increasing Classroom Integration.................... 107

Phase Five: Reimplementation...............................110

IV. DISCUSSION ................................................... 111

V. REFERENCES............................................. 120

VI. APPENDICES .............................................. 136

Appendix I: School Culture and Current Use Survey.....................136

Appendix II: Belief Meets Action Survey ........................138 


\section{ACKNOWLEDGEMENTS}

Though in today's society it often seems cliché, I would like to thank the Lord for his perfect hand in my life. I say this with the utmost reverence for who He is and with a thankful heart for his grace, mercy, and provision. I would also like to thank my family and friends for their patience and support throughout my life, and especially during the time that was invested in reaching this point in my professional life. Thank you to my colleagues who have been immensely supportive and caring during the time I spent working on this project. Finally, thank you to the many professors at Cedarville University who helped to prepare me for what undertaking this thesis would entail, especially Dr. Runyan, who so willingly offered his time and guidance throughout the final stages of this thesis project. 


\section{INTRODUCTION}

Various components of Information and Communication Technology (ICT) have increased dramatically in number and accessibility for the average school across the United States over the past two decades (Bebell, Russell, \& O’Dwyer, 2004). Given the vast promises of ICT to reform and enhance the educational system in the United States (Ayas, 2006), initiatives handed down from federal and state governments (U.S. Department of Education, 2004), and significant investments in hardware and software to equip classrooms (Bebell, et. al., 2004), we would expect to see significant usage of these technologies in classrooms on a daily basis (Casey, 2008). However, research identifies that ICT is only a marginal component in the education of the vast majority of the nation's students; and when it is used, it is not used in a way that fulfills its promise to enhance best practice teaching methods (Cuban, Kirkpatrick, \& Peck, 2001).

Across the nation a generation of "digital natives" is being raised up immersed in the world of ICT (Tondeur, Devos, Van Houtte, Van Braak, \& Valcke, 2009). They live lives "hooked up" to various forms of ICT and other technologies that enhance, and sometimes even create, their daily lives, entertainment outlets, social connections, and planned future endeavors. Information and Communication Technologies have significantly changed the operations of nearly every sector of the United States economy except the school system (Loveless, 1996; Keengwe, Onchwari, \& Wachira, 2008b). Schools have been accused of being entrenched in the Industrial Age, while the rest of the world moves forward into the Information Age, leaving our students behind (Hopson, Simms, \& Knezek, 2001-2002; Lunenberg, 1998). Thus, the question remains: Are 
schools in the United States equipping their students for their futures using the best tools and practices available to them?

Many reasons, ranging from hardware and software availability to teacher reticence, have been cited for this disparity in the availability and utilization of Information and Communication Technology (Groff \& Mouza, 2008). As availability of resources has increased with limited change in their usage, teachers seem to have become the scapegoat for the failure of ICT to live up to its promises (Ferneding, 2003). Accusations of a lack of creativity and innovativeness among teachers (Kurt, 2010), limited technological skills among these "digital immigrants" (Keengwe \& Anyanwu, 2007), and unwillingness to adopt constructivist teaching methods (Prensky, 2008) are among the reasons cited for teachers failing to integrate technology into their repertoire of teaching practices in order to develop, deliver, and enhance their curriculum.

Although research would suggest that teachers are increasingly using technology in their daily lives and for other professional endeavors, it also supports the claim that ICT use for instructional purposes is limited (Bebell, et. al., 2004).

Recent research identifies that this lack of integration is the result of a failure to equip and empower teachers to utilize ICT in a meaningful way in their classrooms. Higher education, prompted by standards handed down from government licensing, has attempted to implement technology instruction into its teacher preparation programs with the hope of rectifying this disparity between personal and instructional use of computers by their teacher candidates (Pasco \& Adcock, 2007). Despite these efforts, there is a lack of transference between learning the techniques involved in ICT integration and actually implementing them into the daily activities of the classroom (Kagan, 1992). 
In addition to these new inductees, a number of veteran teachers remain in the classroom contributing their knowledge of teaching and learning to the field of education. Many of these veteran teachers graduated from teacher candidate programs long before new initiatives to equip teachers to use ICT in their classrooms were developed and initiated in institutions of higher learning. If the investments in ICT are to be put to effective use in the classroom, it is imperative that all teachers be equipped, empowered, and encouraged to use these technologies in their classrooms (Keengwe \& Anyanwu, 2007).

In attempting to increase ICT integration for instructional purposes, it is essential to consider the invaluable role of the classroom teacher. Many studies have identified and supported the claim that teacher beliefs and attitudes play a determining role in the integration of ICT into instructional methods (Polly \& Hannafin, 2010). While government entities and school administrators can identify the importance of ICT integration into the classroom, ultimately it is the classroom teacher who determines the best way to implement the provided curriculum on a daily basis (Cuban, 2006). Though they should not be blamed as the sole reason for the lack of ICT integration in the classroom, classroom teachers are the determining factor when considering the practical implementation of ICT for instructional purposes.

Given this important role of the classroom teacher, adequate professional development is necessary for increased integration of ICT in the classroom (Glazer, Hannafin, \& Song, 2005). Still, defining and providing "adequate professional development" can present significant problems for the majority of schools. Historically, professional development has been delivered in various forms (Mueller, Wood, 
Willoughby, Ross, \& Specht, 2008). Research indicates that the best form of professional development is ongoing, involves content specific directives, and provides significant support during the implementation phase (Lee, 2004-2005). However, this type of professional development can be very costly, so it is often dismissed as an impractical initiative (Russell, Bebell, O’Dwyer, \& O’Connor, 2003; Fletcher, 2006).

With regard to ICT specifically, additional problems for the cost of professional development arise with the significant investments required for the hardware and software itself. It is often taken for granted that once the tools are provided, the teachers will automatically use them effectively (Keengwe, 2007). This fallacy has contributed to the current disparity between availability and utilization of ICT in schools today. Another factor to consider when selecting or designing professional development for educators in the area of ICT is the stages of progression teachers move through in regard to their utilization of ICT in the classroom (Hixon \& Buckenmeyer, 2009). A failure to recognize the various levels of the educators involved in the professional development will result in training that does not fit the current needs of each specific teacher and classroom involved.

In summary, a disparity exists between the current availability and utilization of Information and Communication Technology resources for instructional purposes in the classrooms of United States schools. Despite evidence to identify the benefits of ICT integration in the classroom and significant investments in ICT for the classroom, integration currently occurs at limited rates. Understanding the integral role of the classroom teacher in the integration of ICT to support best practice teaching, it is critical that professional development be utilized in its most powerful and effective form to 
equip, empower, and encourage teachers to integrate ICT into their daily curriculum using best practice teaching methods.

\section{Definition of Terms}

Collaborative Apprenticeship- A model of professional development in which experienced teachers are appointed as mentors to teachers with less experience in the area of technology. Technology integration increases as teachers learn through modeling and collaboration (Glazer, et. al., 2005).

Communicative Technology- Identified as "technology" by the average person, it encompasses devices such as computers, cell phones, iPads, and the Internet (Hlynka \& Jacobson, 2009).

Computer-Assisted Instruction- Instruction that utilizes the computer as an aid to create opportunities for students to learn at their individual instructional level, at a pace controlled by the learner, with immediate feedback, and in a stimulating learning environment (Mautone, DuPaul, \& Jitendra, 2005).

Constructivism- A learning theory based in the work of Bruner, Piaget, Vygotsky, and Papert in which students are viewed as active participants in the learning process (Neo, 2005). Considered by some researchers to be a significant trend in education that attempts to reform how teachers teach and how students learn, in this pedagogical method the student is responsible for their own learning in a teacher developed environment that provides opportunity for authentic inquiry and assessment (Lunenberg, 1998).

Cultural school characteristics- Characteristics of a school that encompass general assumptions, norms, and values shared by members of the school community that 
influence their perceptions, thoughts, and feelings of the school environment (Tondeur, et. al., 2009)

Digital Immigrants- A term that refers to those individuals born after 1980 who may work in the technology world with continuous attachments to their homeland. For example they would prefer to print an attachment to viewing it on the computer screen and are distrustful of common technological tasks (i.e. e-mail), so they would consistently confirm that these tasks were successful. (Prensky, 2001) Digital Natives- Roughly refers to students, or teachers, born after 1980 (Prensky, 2001). These individuals grow up with various forms of ICT ever-present in their lives (Tondeur, et al., 2009). Digital natives may also be referred to as "digital learners" (Simpson \& Clem, 2008). Digital learners are proactive, instant processors who prefer opportunities for random-access instruction, collaborative learning, graphics, and goaloriented, authentic tasks (Simpson \& Clem, 2008).

Educational Technology- "The study and ethical practice of facilitating learning and improving performance by creating, using, and managing appropriate technological processes and resources.” (Januszewski, 2005 II1)

Goal Orientedness- A result of the clear formation, dissemination, and adoption of a school vision by the members of the school community (Tondeur, et. al., 2009). Hardware- The mechanical, electronic, or physical components of a computer system, including: disk drives, circuits, screens, modems, cables, speakers, printers, etc. (http://dictionary.reference.com/browse/hardware, accessed 12/10/2010) 
$\underline{\text { ICT integration- Effective use of ICT tools to accomplish learning goals. It is a process }}$ that involves many diverse factors and changes rapidly with the development of new information and communication technologies (Tondeur, et. al., 2009) Information and Communication Technology (ICT)- Although it can encompass any technological device or development used for gaining information or communicating information with others, it most commonly refers to computers as tools for technology (Tondeur, et. al. 2009).

Information Technology (IT)- A previously used term for Information and Communication Technology (Tondeur, et. al., 2009)

Innovativeness- Describes the ability of concerned parties within a school community to adapt to educational innovations and changes with an open attitude (Tondeur, et. al., 2009).

Instructional Communication Process (ICP)- A model that illustrates the process of communicating information from a source to a receiver through an identified medium. Traditionally, the teacher is the sender, the curriculum is the information, the student is the receiver, and tools used to deliver the message are the medium (Neo \& Neo, 2004). Instructional Technology- Technology used to implement a specific instructional design to achieve instructional ends (Januszewski, 2005)

Internet- A worldwide computer network that connects other computer networks, including government, private and educational networks, using common communication protocols that allow data and information to be accessed and exchanged (http://dictionary.reference.com/browse/Internet, accessed 12/10/2010). 
Leadership- Identifies the extent to which the administration (i.e. principal, superintendent, etc.) of a school community demonstrates supportive behavior (Tondeur, et. al., 2009).

Multimedia- A combination of several types of digital media including text, graphics, sound, or video to provide a multi-sensory interactive experience or presentation when transmitting information to viewers or participants (Neo \& Neo, 2004)

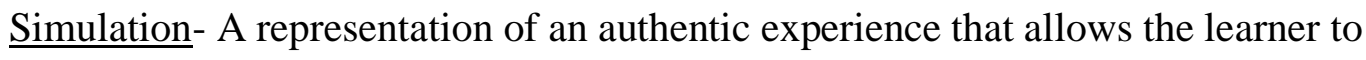
experience and interact with the situation in a safe and controlled learning environment or to view the process in a way that enhances their understanding of a process or event it would otherwise be difficult to observe or experience (Adams, Reid, LeMaster, McKagan, Perkins, Dubson, et. al., 2008)

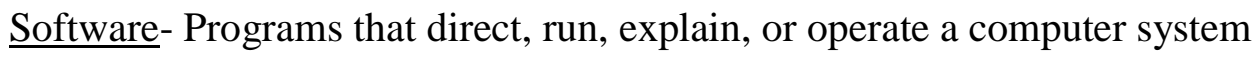
(http://dictionary.reference.com/browse/software, accessed 12/10/2010).

Technocentric- Approaches to technology integration that focus on the technologies themselves rather than student needs, curriculum materials, and disciplinary knowledge. This approach to technology is unaware of the complex nature of ICT integration (Harris, Mishra, \& Koehler, 2009)

Technology- Any application of scientific knowledge for practical purposes (Hlynka \& Jacobsen, 2009). Physical examples of technology are rapidly changing as new advances are made using scientific information and understanding making a clear, accurate definition difficult to ascertain (Cummings \& Buzzard, 2002). Traditional teaching methods- Teaching method involving teacher-centered instruction in which teachers transmit information, skills, and values to students through direct- 
instruction. Most often the entire class is taught as one group and textbooks are used on a regular basis to guide students' daily work (Cuban, 2006).

\section{Statement of Issue}

Economic investments in Information and Communication Technology (ICT) have prompted continuous research in the field since its introduction to schools. The results of this research indicate that ICT is not living up to its promises in the field of education. Traditional research in the field tended to focus on the availability of ICT and only touched on the periphery of teacher and student perceptions. More recent research has focused on developing a greater understanding of the complex myriad of factors contributing to the integration of ICT in the classroom. Within this collection of factors, the important roles of the classroom teacher's beliefs and attitudes toward ICT and educational pedagogy have been established. It is believed that the classroom teacher has the greatest potential to improve the use of ICT in the classroom, but the need still exists to effectively equip these teachers to fully realize the benefits of ICT to their students. Additionally, extensive research has been done on the methods of constructivist teaching and benefits and limitations of professional development. This thesis project will combine the knowledge established through the extensive research completed in the areas of ICT use in schools, constructivist pedagogy, and professional development to design a professional development program with the goal of equipping, empowering, and encouraging classroom teachers to integrate ICT into their curriculums.

Teaching at a relatively small Christian school in rural Ohio has its benefits and challenges. A close-knit atmosphere quickly develops and, along with it, a strong desire to see each child reach their fullest potential. Part of our mission statement is to equip 
and inspire students to be effective leaders in their communities, preparing them for their future station in life. Recognizing that these students will be entering a workforce extensively immersed in ICT, a responsibility exists to insure that each student understands the benefits and limitations of ICT, is able to appropriately use various forms of ICT, and has the skills necessary to effectively participate in the society of the Information Age. A necessary part of this is the use of ICT for meaningful applications directly connected to their learning.

However, integration of ICT in the classroom has been limited to this point. As with many schools trying to function effectively within limited budgets, time has become a priceless commodity to overburdened teachers and the technology funds are invested in providing additional and updated hardware and software programs. Although this school does have a long-term technology plan, the focus is on the acquisition of ICT components rather than the effective integration of them into the classroom. Taking all of these characteristics into account, the professional development program designed through this thesis project will be essential in moving this school to the next level in the effective use of ICT and realizing the expressed desire of their mission statement.

\section{Scope of the Study and Delimitations}

For this project, I have researched prior studies on ICT use in schools, including teacher beliefs and attitudes toward technology, availability and access to various components of ICT, and best practice integration of ICT in the classroom. In addition to my study of ICT, I have researched a comparison of constructivist pedagogy and traditional teaching methods and previous studies on the effectiveness of various forms of 
professional development. This thesis project synthesizes the information collected into a research-based professional development initiative.

This program has been specifically designed for a small Christian school in rural Ohio and will take into account this school's population and ICT availability. The current faculty and staff of this school are comprised of twenty-one teachers and three administrators, all of which can be classified as Caucasian. The administrators are $66.7 \%$ male and $33.3 \%$ female with $100 \%$ having more than five years service in the school. With regard to teachers, $86 \%$ are female, $14 \%$ are male, $71.4 \%$ have over five years teaching experience, $28.6 \%$ have fewer than five years teaching experience, $71.4 \%$ are over thirty years old, and $28.6 \%$ are under 30 years old. Despite the percentage alignments of teaching experience and age, these are not necessarily the same individuals in each category. The current student population has 153 students in grades K-12 who can be described as 90.8\% Caucasian, 5.8\% African American, 2.8\% Asian or Pacific Islander, and less than $1 \%$ Indian. The student population can be further divided into 82 elementary (K-6) students and 71 junior high and high school students (7-12). At the elementary level $56 \%$ of the students are boys and $44 \%$ of the students are girls. At the high school level $42 \%$ of the students are boys and $58 \%$ of the students are girls. Current ICT components include: one portable interactive white board, one stationary mounted interactive white board, four LCD projectors, fifteen student laptop computers with CDRom and USB ports on a portable computer cart, sixteen teacher laptop computers with CD-Rom and USB drives, twenty Netbook computers with USB ports on a portable computer cart, at least two desktop computers in each classroom, wireless Internet access for all laptops and Netbooks, high-speed Internet access for all desktop computers, a 
centralized server, four color printers, one networked black and white laser printer, and one networked copier that can also be used for printing.

This professional development initiative is most directly beneficial to this school, but could easily be generalized and transferred to other schools with similar size, demographics, and ICT availability. Indirect, generalized applications could also be made when developing a program with similar goals in a larger or more diverse setting.

Given the timeframe allotted to complete this project in comparison to the current school schedule, this project relies on theoretical applications of the research for its design. It is based on the assumption that good research and appropriate application of that research will create a successful program. In the future, it would be beneficial to study the effectiveness of this professional development initiative to create lasting change in ICT integration in the classroom. Additionally, because the focus is on the classroom teacher, student attitudes, beliefs, ICT skills, and perceptions of classroom integration will not be fully studied or addressed.

Significance of the Study

Despite the availability of ICT at this school and the development of an extensive technology plan, ICT is not integrated into the majority of classrooms on a regular basis. The current technology plan lacks an understanding of the preeminent role professional development needs to play in order to ensure integration of technology into the standard curriculum. Additionally, with limited opportunities for professional development in general, it is unlikely that the necessary skills for ICT integration will be developed without this project. This professional development initiative has the potential to serve as 
a catalyst for the design and implementation of school-initiated, research-based professional development on other important educational topics.

Given the yearly investments in technology at this school and the school's expressed desire to equip and inspire their students to become future leaders in their community, this professional development initiative will be a significant step forward in being good stewards of the resources the teachers have available to them. It will benefit the students of this school by equipping their teachers to create engaging, authentic lessons using best practice pedagogy. Students will learn skills necessary to participate efficiently and effectively in the Information Age. Additionally, teachers will experience a professional development program designed specifically for them. This program will give them valuable ICT skills, stimulate their innovativeness, establish collaborative discussions with colleagues, and provide ample opportunities for assessing their success in the classroom. Most importantly, it will enable them to use all of the tools available to them to provide their students with the best possible learning experiences.

Whenever attempts are made to require more time of hard-working teachers, some resistance is to be expected. It will be important to help teachers see the value of this program for their professional lives and the lives of their students. If too much resistance is encountered, it may be more effective to begin the program with a smaller number of volunteer teachers rather than a school-wide initiative. Feedback from this initial group of teachers would provide valuable insight for future implementations of this program and the development of other on-site professional development programs. 


\section{Methods of Procedure}

This thesis project began with a comprehensive study of the literature on the topic of ICT use in schools. Additional research was completed on constructivist teaching pedagogy and the effectiveness of various forms of professional development. The information gleaned from the review of the literature is presented in chapter two of this thesis. Data about the demographics and ICT availability in the target school was collected for the project. The study of the literature was then synthesized with the demographics and ICT availability of the target school to create a custom research-based professional development program. The program is explained in detail in chapter three of this thesis. Finally, chapter four of this thesis offers a discussion of the program development, including implications for future analysis and study. 


\section{PLENARY LITERATURE REVIEW}

The use and presence of technology in education is as old as the field of education itself, beginning with more simple tools like chalk and slates and progressing toward the more complex tools of personal computers and their hardware and software components. These technological contributions to the field of education are the result of passionate innovators and scholars who have sought to enhance the educational system of the United States (Hermans, Tondeur, van Braak, \& Valcke, 2008). For the purposes of this thesis project, we will focus on the technological innovations that can be encompassed under the umbrella of Information and Communication Technology (ICT). Governmental Policy and History of ICT in Education

Attempts to involve ICT in the educational arena began with the invention of the personal computer (Fazarinc, S. Divjak, Korošec, Holobar, M. Divjak, \& Zazula, 2003). Fazarinc, et. al. also point out that many subsequent inventions to make the personal computer more user-friendly were spawned due to the desire to see the computer put to use in educational settings. The first computers entered the world of education during the 1970s (Keengwe, et. al., 2008b). During the 1980s, additional inventions that aided the use of personal computers also entered the field of education (Keengwe, et. al., 2008b). Finally, the Internet came on the scene during the 1990s (Keengwe, et. al. 2008b), further securing the rise of the Information Age.

Along with the increasing presence of the Internet, other inventions in the field of ICT were being combined to increase the accessibility and usability of ICT for 
educational purposes. Teachers began using technology in additional ways both inside and outside of the classroom (Bebell, et. al., 2004). Of note is the fact that while the innovations of new ICT and their introduction to educational institutions were in full swing, the integration of these technologies into the process of learning was not observed in most of the nation's classrooms (U.S. Department of Education, 2004).

The increasing availability and promises of ICT in the classroom prompted investigations into how ICT was utilized in classroom settings. Historically, ICT use was categorized into the following three categories: tutor or computer-aided instruction, tool, and tutee (Wentworth \& Earle, 2003). The computer as a tutor included drill-andpractice type programs (Wentworth \& Earle, 2003). The computer as a tool encompassed such activities as word-processing and researching databases of information (Wentworth \& Earle, 2003). The computer as a tutee involved the student programming the computer (Wentworth \& Earle, 2003). More recent inspections have categorized computer-use by teachers into the following activities: creating instructional materials, keeping administrative records, communicating with colleagues, gathering information for planning lessons, presenting multimedia presentations, accessing research for best practice teaching, communicating with parents and students, and accessing model lesson plans (Bebell, et. al., 2004). The results of this research indicate that computers are being used in significant ways to support teaching outside of the classroom but in limited ways to support learning in the classroom (Bebell, et. al., 2004). Based on this understanding of current ICT use in classrooms, recent efforts in ICT use for education have focused on encouraging teachers to use technology to support learning in the classroom (Frye \& Dornisch, 2007-2008). 
Research would indicate that this focus is well-placed. Despite many promises of ICT to enhance, even reform, the educational system in the United States, ICT is not being used in the classroom in ways that develop meaningful learning opportunities or fully realize its proclaimed potential (Keengwe \& Anyanwu, 2007). Even so, the everpresent components of ICT and continuing research on ICT remind us that computer technology continues to advance and influence the way students learn (Keengwe \& Anyanwu, 2007). With three decades worth of investments, advancements, and research into the use of ICT in classrooms, many stake-holders in the field of education understand the potential for the use of technologies in the classroom (Allen, 2008). Now, a shift in focus is being made to understanding how to prepare teachers to select and use appropriate components of ICT to achieve the goals they have for their students (Keengwe, et. al., 2008b). The goal of these various stake-holders, including teachers and policymakers, is the continued advancement of the U.S. educational system and its ability to provide a high-quality education for America's students (Culp, Honey, \& Mandinach, 2005).

In 1983 the Commission on Excellence in Education published the A Nation at Risk report (Ferneding, 2003). Included in A Nation at Risk, were a list of basics that should be covered before high school graduation, including computer science (Culp, et. al., 2005). A Nation at Risk also pointed out the importance of innovativeness in the future success of the nation (U.S. Department of Education, 2004). Some have questioned the arrogance of A Nation at Risk in identifying the school system as the root of the nation's economic struggles (Ferneding, 2003). Nevertheless, it has served as a springboard for educational reform in the United States. Since the time of this report 
nations around the world, including the United States, have maintained continuous policy making that includes the use of ICT in classrooms (Selwyn, 2008). Despite the progress that the United States has made since A Nation at Risk (Culp, et. al., 2005), there has been a push to move technology from computer class and integrate it within the general curriculum for all students (Allen, 2008). Although all of the governmental reports on technology recognize the importance of hardware accessibility and reliability, many reports also draw attention to other factors involved in technology integration (Culp, et. al., 2005). In fact, the A Nation at Risk report identified the importance of having highly qualified teachers in the classroom, and the 2000 National Technology Plan identified the importance of improving the training of teachers to enhance technology integration (Culp, et. al., 2005).

A Nation at Risk began one of the most continuous periods of government fed national reform in the United States educational system, and since its passage many other pieces of legislation have attempted to continue this reform (Lunenberg, 1998). The Goals 2000 Educate America Act was passed in 1994. Among other things, the act requires that students demonstrate competency in core subject areas and learn to use their minds well (Lunenberg, 1998). Many feel that constructivism and technology integration offer the most promise for fulfilling these goals (Lunenberg, 1998). The National Assessment of Educational Progress is used to assess the nation's progress in fulfilling these goals.

In 2001 the No Child Left Behind Act was passed with bipartisan support in Congress. President Bush signed the act into law in January of 2002 (U.S. Department of Education, 2004). This act hoped to save children lost in the educational system and 
abolish illiteracy (U.S. Department of Education, 2004). With No Child Left Behind the government introduced more stringent accountability standards for the educational system and cited the importance of using research to fuel reform (U.S. Department of Education, 2004). It also increased expectations of students with the hopes of thwarting the tendency to pass children along to the next grade and teacher (U.S. Department of Education, 2004). Research also indicates that along with traditional literacy skills, it is also important to help students develop appropriate electronic literacy skills (Labbo, 2007).

In 2002 the National Council for Accreditation of Teacher Education (NCATE) included technology in their standards for teacher preparation courses, focusing on six skills areas in order to effectively use technology with students and colleagues (Pasco \& Adcock, 2007). In addition, the National Educational Technology Standards for Teachers include 23 indicators of appropriate preparedness for teacher candidates (Pasco \& Adcock, 2007).

The National Education Technology Plan was presented in 2004 offering recommendations in seven key action areas for states, districts, and schools to use when developing their own long-term technology plan (U.S. Department of Education, 2004). The seven key areas include: strengthening leadership, innovative budgeting, improving teacher training, supporting e-learning and virtual schools, increasing broadband access, moving toward digital content, and integrating data systems (U.S. Department of Education, 2004). This project will focus on the recommendations for leadership and teacher training. The recommendations for leadership include: developing tech-savvy personnel at every level of leadership, developing administrator education programs that 
include training in technology decision making, encouraging creative partnerships with local businesses, and including students in the decision-making process (U.S. Department of Education, 2004). The recommendations with the most application to this project were the recommendations for teacher training. These recommendations include: improving teacher preparation for the use of new technology, offering every teacher the opportunity to take online learning courses, improving the quality and consistency of teacher education, and ensuring that teachers are able to access and interpret data to personalize instruction (U.S. Department of Education, 2004). These recommendations are indicative of a developing push to provide professional development for teachers to increase the integration of technology in the classroom (Frye \& Dornisch, 2007-2008).

Also in 1994, the National Education Association collected data from students and teachers to develop an understanding of the use of technology in the classroom (Tuck, 2004). This collection of evidence identifies major gains and gaps in the use of technology in schools (Tuck, 2004). Major findings of the study included the following (Tuck, 2004):

- Most educators had access to computers, but student access in the classroom was limited.

- Educators were involved in technology purchases, but still felt that upgrades and support were insufficient.

- Educators were more familiar with educational technology, but were ill-prepared to use that technology for instructional purposes. 
- Training was inadequate to prepare and encourage integration in the classroom.

- Gaps still existed based on demographics.

- Educator attitudes toward technology are variable over time.

Based on these major findings, the following recommendations were given (Tuck, 2004):

- Make computers available in the classrooms that provide regular access throughout the school day.

- Provide adequate staff development, equipment upgrades, and technical support to encourage broad-scale integration.

- Include the staff in decision-making about all areas of school technology, including training and professional development opportunities.

- Ensure that pre-service and in-service teachers are adequately prepared to integrate technology in their classrooms.

- Close disparities between demographic groups.

- Upgrade and maintain equipment in impoverished school districts.

- Encourage further research and development of technology programs.

Evidence supports the political commitment to improve the quality of education that our nation's students receive and the importance that increased integration of 
technology in the classroom will play in achieving these lofty goals and stresses the importance of preparing schools and teachers to utilize the technology available to them (Joshi, Pan, Murakami, \& Narayanan, 2010). Additionally, these goals are not just for certain levels of students. The National Association for Education of Young Children stressed the importance of integrating computers beginning at the early childhood level (Joshi, et. al., 2010).

The federal government and other national organizations have developed curriculum standards that focus on high-order thinking skills, authentic tasks, and technology integration to support learning (Polly \& Hannafin, 2010). These skills include critical thinking, inquiry, and collaborative problem-solving in every subject area (Polly \& Hannafin, 2010).

Many states, including Ohio, have also adopted technology standards to encourage the use of technology in highly effective schools. Ohio adopted their technology standards in December 2003 (State of Ohio Board of Education, 2003). The expressed goal of these standards is to identify what students should be able to know and do in technology (State of Ohio Board of Education, 2003). The process of developing these standards began in 1997 and Amended Substitute Senate Bill 1 added the area of technology to the list of subjects for standards to be developed (State of Ohio Board of Education, 2003). These standards are based on the National Education Technology Standards for Students and were reviewed by national experts to ensure their appropriateness and clarity (State of Ohio Board of Education, 2003). They address a broad spectrum of technologies, including ICT, that are divided into three categories: computer and multimedia literacy, information literacy, and technological literacy (State 
of Ohio Board of Education, 2003) with the goal of equipping schools to prepare their students to meet the Eighth Grade Technology Literacy requirement of No Child Left Behind (State of Ohio Board of Education, 2003). Seven standards are delineated with benchmarks and indicators as follows (State of Ohio Board of Education, 2003):

- Nature of Technology

- Technology for Society Interaction

- Technology for Productivity Applications

- Technology for Communication Applications

- Technology for Information Literacy

- Design

- Designed World

Standards have an important role to play in technology integration. Standards delineate specific goals and expectations to be sought and met and provide political momentum for reform movements (Gordon \& Still, 2007). Universities and governmental organizations alike recognize this need for specific standards in order to align their programs (Donaldson, 2009). Important to note is that due to the fluidity of the field of technology, it is imperative to continuously evaluate these standards (Donaldson, 2009). The Ohio Academic Content Standards, including those for technology, sought to create this important framework (State of Ohio Board of Education, 2003). In regard specifically to the technology standards, they sought to provide a foundation for technological achievement (State of Ohio Board of Education, 2003). They offer these as a "set of common expectations upon which to base technology curricula" (State of Ohio Board of Education, 2003). The State of Ohio Board of 
Education (2003) identifies the following principles as guiding factors when developing the state's technology standards: high expectations for all students, alignment with national technology standards, successive transitions between grades, a focus on important concepts, active and authentic learning, guided curriculum decisions, and ability to become a basis for assessments. Although it is important to recognize the reality that standards alone will not ensure good methodology (Gordon \& Still, 2007), standards can provide a baseline for establishing proper content and methodology.

Within the broader constructs of the Ohio Academic Content Standards for Technology, specific goals are given for all students to achieve. Within the area of computer and multimedia literacy, students would be expected to use hardware, software applications, and multimedia tools in appropriate ways to accomplish educational tasks (State of Ohio Board of Education, 2003). Information literacy involves the ability to locate, interpret, and utilize information for research and knowledge building (State of Ohio Board of Education, 2003). Technological literacy refers specifically to unique abilities required for participation in a technological world, including the connections between technology and career choices (State of Ohio Board of Education, 2003). The philosophy behind these standards is that "learners will become capable problem-solvers and creative thinkers who are prepared to adapt to changing environments, educational challenges, and career opportunities" (State of Ohio Board of Education, 2003).

The importance of literacy within these standards is evident. In the Information and Technological Age, literacy becomes even more essential, not just in understanding text, but also the possession of the ability to discern accuracy and usefulness for a given situation (Gordon \& Still, 2007). The school system in the United States was designed to 
serve students in an era of U.S. history that has become known as the Industrial Age. Today's students, however, no longer fit that mold (Prensky, 2001). Today's students are known as "digital natives" and they require a new set of skills to participate in a new structure known as the Information Age (Shepherd \& Mullane, 2010). Teachers and students must now learn to view components of ICT as tools rather than toys (Shepherd \& Mullane, 2010). Students can complete tasks at higher levels when they are equipped to use ICT as a tool, but students and teachers alike need appropriate training to select the best technological tool for the task at hand (Shepherd \& Mullane, 2010). This generation constructs and understands meanings through various mediums, including music and images in addition to printed text (Shepherd \& Mullane, 2010). This has developed an entirely new set of literacy skills that students need to learn and cultivate in order to become active participants in the Information Society.

Students today have to learn how to access the information, but they must also learn the necessary skills to sort through and use the information to accomplish their tasks (Kurt, 2010). Much research has been done on the development of literacy skills. One such study indicates that literacy has cultural, creative, and social applications (Partington, 2010). Media literacy works in a similar way to traditional literacy in that it is critical and requires a specific set of skills, including an understanding based on social context (Partington, 2010). Following his study on gaming literacy, Partington (2010) concluded that it is imperative for teachers to engage students in activities that are a part of their culture and scaffold ideas that allow students to learn from their experiences.

In their work on new literacy, Mokhtari, Kymes, and Edwards (2008) investigate how current models of reading and writing translate to online literacy. Their research 
identifies that online and offline reading are very different. Online reading enables instant communication about the issues students are studying and the purposes for reading are often different than the reading of traditional printed text (Mokhtari, et. al., 2008). Necessary literacy skills range from knowing which search engine to use to critically evaluating the information that is found (Mokhtari, et. al., 2008). Mokhtari, et. al. identify that online reading comprehension skills involve the following five areas: generating a social problem or question, locating information, critically evaluating information, synthesizing information from multiple sources, and communicating information with others. However, the National Assessment for Educational Progress will not assess for these skills until after 2019 (Mokhtari, et. al., 2008).

One marked difference between traditional literacy and electronic literacy is in the passivity of traditional texts and the interactivity of electronic texts (Pearman, 2008). Electronic texts allow the reader to hear the text, hyperlink to other explanations or connecting data, and control the flow of the text (McKenna, Reinking, Labbo, \& Kieffer, 1999). While electronic texts must be utilized carefully with struggling readers (Pearman, 2008), especially in reference to the potentially bewildering set of options (McKenna, et. al., 1999), some text features may offer computer-aided, individualized instruction for struggling readers (Labbo, 2007). Translation resources and illustrations can provide scaffolding help to struggling readers if used in an appropriate manner, but just as with traditional text it is important to recognize the major stages that students move through in regard to reading ability: initial reading and decoding, confirmation and fluency, reading for learning, multiple viewpoints, and developing a world view (McKenna et. al., 1999). 
In addition to changing, or at least enhancing, the skills necessary for reading electronic texts, increased use of the Internet has made changes in the necessity for developing writing skills for effective online communication (Karchmer-Klein, 2007). Electronic text is different than traditional prose in that it allows for many advanced features such as sound, font changes, graphics, and hyperlinks to be used (KarchmerKlein, 2007). Students must develop the capabilities to use these features in their writing in order to accurately convey their thoughts to their readers (Karchmer-Klein, 2007). Suggestions have been made that the use of classroom websites will contribute to the development of both reading and writing portions of electronic literacy (Karchmer-Klein, 2007).

As identified in the aforementioned research, it is important that students learn to access and use the seemingly limitless information available to them courtesy of ICT (Salpeter, 2008). Today's students possess the basic skills necessary to utilize computers as toys, but they must be trained in search skills, analysis, and online ethics in order to effectively use them as tools (Salpeter, 2008). Though ICT rapidly changes, teachers can effectively equip their students to be critical thinkers with regard to the information they are able to access via ICT technologies (Baker, 2007). Likewise, other opportunities for developing these new literacy skills seem to be relatively limitless given the information available via the Internet (Baker, 2007).

Though some critics question the responsibility of the educational system to cater to society as a whole and cite the computerization of society as the force behind including the computer in the classroom, even they must also admit that developments in ICT are creating changes in the lives of those involved in the educational system (Ferneding, 
2003). Ferneding also identifies that the purpose of education in the Information Age has been redefined resulting in a need for the integration of ICT into the educational system. Students growing up in this Information Age need to develop a set of skills different from students of the past. These students need to function in a global marketplace where technology skills, critical thinking capabilities, and the ability to effectively access and utilize information are prerequisite skills for success (Culp, et. al., 2005; Baker, 2007). Projections for the future suggest that global competition will continue to increase in the future and recognize that this competition will require increasing ICT skills (U.S. Department of Education, 2004). America's students need to be equipped to participate in this global market economy (U.S. Department of Education, 2004).

The United States Department of Education (2004) also recorded the voices of students when developing the National Education Technology Plan. Given that it is there future at stake and to get a better perspective on these "digital natives" to be educated in this newly evolving educational system, these voices provide valuable insight to the study of the integration of ICT into classrooms. Major themes identified from student comments included a description of students as tech-savvy students who value and prefer the use of technology in every aspect of life. Also identified were that their daily activities were different because of technology, the bulk of their computer access occurs at home, and they are ultra-communicators. These students expressed the desire to use computers to learn at school and the need for teachers to be equipped to teach using computers. These students see the potential for ICT use in schools, but also recognize the need for teachers to receive the training to realize this potential (U.S. Department of Education, 2004). 
Few would argue the fact that we live in a technological world and that the tools of ICT are becoming a part of the way we teach and learn today (Ayas, 2006). Today's students love to do, discover, and interact with their environment. These activities make learning more fun. Some would argue that it is not a question of should we use technology, but how can we best use technology to enhance the learning of our students (Ayas, 2006). In addition to equipping students to become participants in a technological world, research supports the use of ICT to increase student motivation and performance (Ayas, 2006). Frye and Dornisch (2007-2008) indicate in their study on student evaluations of ICT use that students favor the more interactive approach that the use of ICT seems to lend itself to over more traditional forms of learning. Still, it is imperative that we continue to recognize technology as a tool and recognize the critical role of teachers who will decide how to best utilize this tool in preparing their students for their futures (Casey, 2008).

Given this information it is apparent that ICT can provide tools for educational reform and improvement (Ayas, 2006). The U.S. Department of Education (2004) indicates that our nation is seeking change and that the constructivist movement will continue to be fueled through ICT integration. Their reasoning for this reform is to see that all students are able to succeed and receive a quality education. Educational reform finds its foundation in two basic assumptions: students of the U.S. have a lower academic achievement level than students of other world countries and the Information Age requires a new skill set to ensure competitiveness in this global economy (Ferneding, 2003). The merger of these two goals has created a technocentric approach to reform (Ferneding, 2003). To be fair, Ferneding cautions against whole-heartedly accepting ICT 
as a tool without cultural bias and points to the importance of understanding the cultural influences at play when making technocentric reforms. A key point in this awareness is the acknowledgement that acquisition of ICT components will not inherently create reform. Teachers must be equipped to use the tools in ways that align with best practice pedagogy (Ferneding, 2003). In short, how you use the technology is just as important as having the technology.

Given the two assumptions stated above, it is not surprising that one of the most common reasons given in support of reform is the need to effectively prepare students for adulthood (Hopson, et. al., 2001-2002). Listed among the skills necessary for success in the Information Age are problem-solving, critical-thinking, and higher-order thinking skills and the integration of ICT is viewed as a tool with the potential to develop these skills when used in conjunction with constructivist teaching (Hopson, et. al., 2001-2002). Additional goals of reform include making schools efficient and transforming the teaching-learning process into an active experience on the part of both teachers and students (Solhaug, 2009). The use of ICT alone will not promote reform in the educational system, but it is believed that the use of ICT can work as a catalyst to encourage the use of constructivist teaching methods rather than more traditional teachercentered approaches (Culp, et. al., 2005).

Labbo (2007) suggests that the reason computers catalyze change is that they provide a unique, efficient, and creative approach to problem-solving. Labbo (2007) also suggests that ICT components can create student-centered learning environments that motivate students to seek after knowledge and take control of their own learning. Frye and Dornisch (2007-2008) also identify that successful integration of technology carries 
with it a tendency towards student-centered teaching. Additionally, the Internet provides enhanced communication that increases feelings of ownership among students (Solhaug, 2009). Further cementing the relationship between constructivism and ICT integration, Gordon and Still (2007) identify that constructivist teaching carries with it the inherent proclivity toward the inclusion of ICT as a tool for authentic learning tasks and points to the potential for ICT to serve as an intellectual partner in scaffolding during learning tasks. In fact, constructivist beliefs of teachers had a strong correlation with ICT integration in the classroom (Hermans, et. al., 2008).

This current trend toward constructivist teaching has opened doors for the integration of technology because technology is viewed as the vehicle for enacting the change from traditional, teacher-centered classrooms to constructivist, student-centered classrooms (Hermans, et. al., 2008). ICT is credited with the potential to bring about this constructivist revolution (Hermans, et. al., 2008).

Further support for the use of ICT in education reform comes from the positive correlation between ICT integration and student achievement, attitudes, and self-esteem (Keengwe, et. al., 2008b). Keengwe, et. al. continues to point out the importance of using technology as a tool to complete appropriate and authentic tasks and the importance of using ICT alongside best practice, student-centered constructivist teaching. Admittedly, the potential of ICT exists only in its proper usage, but when it is used appropriately the opportunities for educational reform are nearly limitless (Keengwe, et. al., 2008b).

Though ICT can serve as a catalyst, it is not a magical cure to fix all of the problems of the educational system (Keengwe, et. al., 2008b). The most important 
resource for reform in the classroom is the teacher, and those teachers must be prepared to utilize the ICT that is available in their classroom in authentic and effective ways (Keengwe, et. al., 2008b). ICT is popular because teachers believe in the potential of ICT to improve student learning, but evidence identifies that ICT integration only improves the educational experiences of students if it is used in effective, constructivist ways (Keengwe, et. al., 2008b). Thus, the greatest need to achieve the desired educational reform is the preparation of teachers to utilize all the tools available to them in a way that promotes best practice pedagogy so that instruction guides the selection of appropriate tools (Keengwe, et. al., 2008b). Teachers have a unique and invaluable role to play in the integration and effectiveness of ICT in the classroom (Keengwe, 2007).

Still, some educators caution that reform does not happen overnight and we should be aware of faddish changes that reflect the ever-changing attitudes and desires of the public (O’Neil, 2000). Additionally, O’Neil in his interview of Larry Cuban, records Cuban's caution that reforms with the least chance of sticking are those that attempt to change the way teachers teach. If policy makers intend to transform education from traditional to constructivist teaching, it is imperative that teachers are involved in the decision-making process and equipped to carry out the changes within the classroom over the long term (O’Neil, 2000).

Cuban, et. al. (2001) also point out that current studies on technology use in classrooms identify that teachers maintain current pedagogy. They note that historical attempts at reform have failed due to their focus on policy makers rather than on the teachers who would be carrying out those reforms. If the current push for educational reform is to be lasting, teachers must be equipped and empowered to make the necessary 
pedagogical changes (Cuban, et. al., 2001). Prensky (2008) also points out that many teachers see this change as enormous and the hope of change rests on the shoulders of those who believe in the potential of constructivist teaching and ICT integration. Prensky suggests that three things will be required for the majority of teachers to make this pedagogical shift: examples, support, and success.

At the risk of stating the obvious, significant investments in ICT have been made in schools across the nation over the past few decades (Bebell, et. al., 2004). The constructivist reform movement that hangs its tenants on the promises of ICT integration in the classroom has spawned increasing expenditures in technology (Kromhout \& Butzin, 1993). Proponents of ICT investments justify these expenditures across three key ideas: technology is a tool that can address the challenges of education, technology can serve as a catalyst for constructivism, and technology plays an increasingly significant role in the global economy (Culp, et. al., 2005). As schools continue to invest in components of ICT, it is important to determine the effectiveness of these investments in regard to student learning (Keengwe, et. al., 2008b). Research indicates that in many classrooms across the country, computers have become rather expensive dust collectors that merely take up space in the classroom (Kromhout \& Butzin, 1993). Some have questioned the expectation that providing the components of ICT will automatically lead to their effective use, and stress the point that a re-appropriation of ICT funds to include teacher training is called for (Cuban, et. al., 2001; Keengwe, et. al., 2008b; Keengwe, 2007). The U.S. Department of Education (2004) suggests that the problem with ICT integration is not funding for ICT, but how those funds are allocated and a failure to understand how to use the technology to promote best practice teaching. Likewise, Culp, 
et. al. (2005) suggest that ICT funding be spent across seven areas: improving access and infrastructure, creating and purchasing high-quality software, providing sustained professional development, increasing funding from various sources, promoting the roles of public and private stakeholders, increasing research, and continuously reviewing the local purchasing and use of ICT in the classroom.

The fact remains that although ICT is often touted as the savior from an out-dated educational system (Ferneding, 2003) and the catalyst for the reformation of that system (Hermans, et. al., 2008) the realization of these goals is yet unseen (Fazarinc, et. al., 2003) despite significant investments and political support of ICT integration and reform (Keengwe, et. al., 2008b). The time has come to stop looking back and begin looking forward by equipping teachers to use the most effective tools to provide the best education possible for their students (Shepherd \& Mullane, 2010).

\section{Promises of ICT Use}

Though evidence suggests that ICT is not being used at its fullest potential and that the most effective use only begins in the final two stages of progression in ICT integration, one researcher suggests that an important selling point for the use of ICT is that it is now possible to begin using ICT in the classroom without changing pedagogical practice at the same time, thereby allowing teachers to progress toward best practice use of ICT technology at their own pace (Chaptal, 2002). Extensive research has been completed that offers findings that support the advantages of ICT integration in the classroom (Kurt, 2010). Gimbert and Cristol (2004) identify that the promise of ICT lie in the ability to improve teaching and learning. These proposed advantages of 
technology have been the justification for the seemingly endless investments hoping to support ICT use in the classroom (Milliron \& Miles, 1999).

One such advantage often cited by proponents of ICT integration is its ability to breathe life into an outdated educational system by developing more creative and innovative lessons (Milliron \& Miles, 1999). Okan (2007) explains that ICT has the potential to improve the way that students learn. Zhao (2006) outlines the importance of using creativity when teaching and fostering creativity in students. Frye and Dornisch (2007-2008) identify that the integration of ICT in the classroom can often lead to more creative and interactive lessons. The research of Hopson, et. al. (2001-2002) supported the claim that ICT integration has a positive effect on the development of higher-order thinking skills in students. Neo (2005) identified the success of ICT in helping students to develop critical thinking, creative thinking, and problem solving skills, while simultaneously developing their metacognition and collaboration. The importance of using interactive multimedia applications in the classroom to foster creative and innovative learning has also been established (Neo \& Neo, 2004). In addition to researchers, many educators also believe in the creative potential of ICT to provide active, authentic, and more enticing learning experiences for students (Keengwe, et. al., 2008b). Despite its potential to bring creative and innovative changes to the classroom, these will only become reality when ICT is combined with best-practice, constructivist teaching (Gentry, 2008).

In addition to the promises of ICT to increase creativity and innovativeness, research also identifies the potential of ICT to increase collaboration in learning based on the assumption that learning begins on a social level (Järvelä, Veermans, \& Leinonen, 
2008; Clements \& Sarama, 2003). Though support would have to be given to some students, socio-constructivist learning enhanced by ICT scaffolding has the potential to increase collaborative learning, decision-making skills, ownership, and social skills in students (Järvelä, et. al., 2008). The access to information and interactivity that ICT communication can provide helps improve student learning (Solhaug, 2009). In research on the use of simulation games in the classroom, the potential for social interaction is identified alongside intervention and authenticity (Simpson \& Clem, 2008). Simpson and Clem also reported findings based on student journals kept during the simulation activities that indicate student perceptions of collaboration during the activity. Schrand (2008) also identified that the use of interactive multimedia improved student participation and interaction even in a large group setting.

In addition to student collaboration, ICT also has the potential to increase the collaboration of teachers and other educational professionals. In the early childhood classroom ICT is identified as serving as a catalyst to encourage collaboration between teachers and parents, as well as inter-student collaboration in learning (Gimbert \& Cristol, 2004). This collaborative teaching leads to increased professional development, meaningful pedagogical changes, and more effective ICT integration (Gimbert \& Cristol, 2004). Accessibility to information on the Internet also increases the potential for collaboration between professionals in various fields of education (Doolittle \& Hicks, 2003). Still, some researchers believe that teachers are not completely aware of the collaborative potential of ICT for professional growth (Lim \& Chai, 2008).

Another concern of teachers with regard to collaborative ICT learning is that it is difficult to assess student learning (Lim \& Chai, 2008). Despite the difficulty of 
assessing collaborative learning through ICT, it does hold promise to increase collaborative learning through the consideration of individual needs (Mavrou, Lewis, \& Douglas, 2010). Collaboration among teachers is essential to developing positive feedback on the collaborative use of ICT in education. Collaboration and negotiation are important to the educational experience, and teachers have a key role to play in facilitating communication between students that enhances the combination of the various sets of background information and experiences individual students bring to the collaborative learning experience of the classroom (Gall \& Breeze, 2008).

Along with innovativeness and collaboration, researchers have also explored the role that ICT has the potential to play in regard to intervention for individual abilities. As identified in the previous paragraph, ICT holds the promise to adjust its questions and requirements based on individual levels, needs, and capabilities (Mavrou, et. al., 2010). Keengwe, et. al. (2008b) described the promise of computers as tools for students with disabilities, meeting individual needs, and making abstract concepts more concrete when competent educators design lessons that effectively use ICT.

Gentry (2008) identified the desires of educators to explore the promise of ICT to support students in the act of writing. Englert, Manalo, and Zhao (2004) researched the effect that the use of ICT for scaffolding would have on students' abilities to complete the abstract task of writing. They identified three ways in which ICT can provide scaffolding for the writing process: highlighting text structures like sequencing and genre types, supporting communication, and giving prompts for completing each step (Englert, et. al., 2004). The results of this research supported the use of ICT in the education of 
young or struggling writers (Englert, et. al., 2004). It is also expected that CAI can encourage fluidity in the writing of young students (Clements \& Sarama, 2003).

McKenna, et. al. (1999) similarly investigated the promise of using ICT to aid struggling readers. They identified that guidance could be built into the software that is used in the classroom to provide pronunciation, definitions, examples, and illustrations that would assist struggling readers in understanding a given text (McKenna, et. al., 1999). Clements and Sarama (2003) identify the hope of ICT to help close the gap in reading ability caused by environmental factors in early childhood education. Though the use of ICT for reading intervention can create some challenges, research argues that the promises of ICT to effectively aid struggling readers outweigh their challenges and costs (McKenna, et. al., 1999).

Similarly, Mautone, et. al. (2005) acknowledged that computer-assisted instruction (CAI) holds the promise to allow individuals to learn various curriculum materials at their own pace and level with immediate and consistent feedback. Their research determined that CAI was effective in providing intervention for students diagnosed with ADHD in the area of mathematics (Mautone, et. al., 2005). The results of research on ICT use in the social studies classroom indicate that students in each of three ability groups (special needs, gifted and talented, and regular education) showed improvement in their knowledge and understanding of topics covered, with the most significant improvement recorded in the gifted and talented group (Gentry, 2008).

Additionally, when ICT lessons are effectively designed and implemented they can provide interactive authentic lessons that align with the varied learning styles and preferences of the myriad of students in each classroom (Choi, Lee, \& Jung, 2008). 
Blagojevic (2003) similarly identifies the possibilities of ICT in meeting the individual learning styles of students in her research on the funding of ICT programs in early childhood settings. In their research on the use of video simulation games in the classroom, Simpson and Clem (2008) identified increased motivation due to the video game adjusting to individual abilities and providing immediate feedback. Okan (2007) also cited the abilities of ICT to provide individualized instruction that meet specific learner needs.

Research has documented the effectiveness of ICT integration when it is used deliberately and appropriately. For example, educators understand the importance of timely and complete feedback for students in creating an effective learning environment. In their research on computer-mediated feedback, Boling and Beatty (2010) documented how the use of a computer aided in providing ongoing, formative assessment and cognitive modeling in an Advanced Placement English course. In another example, Ke (2008) designed a study to test the conflicting results of studies on the use of computer games to improve student mathematic performance. While Ke's study only partially supported the effectiveness of computer games on learning outcomes, it does illustrate the potential of using ICT as a tool to complement best-practice teaching and support the technique of using ICT to increase student motivation. Lin (2008) also investigated the effect of using ICT in the mathematic classroom. Lin conducted interviews of teachers who, through a workshop experience, had attempted to use ICT when teaching mathematic concepts. All of the participants indicated that the computer and web resources played a significant role in helping the students learn and increasing student motivation (Lin, 2008). 
Perhaps one of the most significant longitudinal studies on the effectiveness of ICT integration in the classroom has been Project CHILD (Butzin, 2000). Project CHILD encompassed a decade of research demonstrating the effectiveness of technology in the classroom (Butzin, 2000). Created by Florida State University in 1988, the goal of Project CHILD was to create classrooms where innovation and technology integration were an integral part of the classroom environment (Butzin, 2000). Project CHILD involved a classroom designed to utilize technology in a constructivist environment (Butzin, 2000). Kromhout and Butzin (1993) identified seven key components to the Project CHILD program: multi-grade continuous progress classroom clusters, multidimensional classroom learning stations, student empowerment, systemic classroom management procedures, use of multiple assessments, and parent involvement. The role of ICT in the program was extending instruction, maximizing time on-task, and proving feedback (Butzin, 2000). Results of this study record consistently higher test scores from Project CHILD students over traditional classrooms in mathematics and reading (Butzin, 2000; Butzin, 2001). Results also indicate that the effects may be cumulative relative to the length of time a student spends in the Project CHILD program (Kromhout \& Butzin, 1993).

Aside from testing scores, another expected result of ICT integration in the classroom is increasing computer skills in students (Frye \& Dornisch, 2007-2008). Blagojevic (2003) identifies that computer and other ICT skills are important for students to have in an Information Age economy. A positive correlation between computer proficiency and academic achievement has been identified, including increased achievement in all subjects, improved attitude, and increased self-esteem in the classroom 
relative to computer skills (Keengwe, et. al., 2008b). Clements and Sarama (2003) identify that ICT can have a significant impact on student learning when it is used well. Important to note, however, is that teacher proficiency with ICT significantly determines the effectiveness of its use in the classroom (Chen \& Chang, 2006).

In order for ICT integration to have a positive impact on the education of students, teachers must strongly believe in its capabilities and use ICT as a tool to take advantage of and enhance learning opportunities (Silman \& Gündoğdu, 2007). In short, research provides support for the effectiveness of ICT integration when it is used by skilled teachers as a tool to facilitate and enhance their teaching (Silman \& Gündoğdu, 2007; Butzin, 2001). Additionally, it is most effective when used in a constructivist classroom as opposed to a traditional classroom (Butzin, 2001). As Milliron and Miles (1999) determined, the Internet hasn't changed effective education, but it can be used to enable best-practice education.

Hopson, et. al. (2001-2002) conducted research investigating the impact of ICT integration on higher-order thinking skills and student attitudes toward technology. They identified that the use of ICT integration did have a positive effect on student development of higher-order thinking skills (Hopson, et. al., 2001-2002). Even stronger were the results indicative of ICT integration creating classroom environments more student-centered, cooperative, and tending toward application than traditional classrooms (Hopson, et. al., 2001-2002). This indicates that the technology was a tool in creating a more constructivist environment, thereby enhancing higher-order thinking skills (Hopson, et. al., 2001-2002). According to Neo (2005), constructivism and ICT work together to create a best-practice learning environment that will encourage students to be active 
participants in their educational experience and aid them in the development of the skills necessary for their future success.

ICT is changing the way teaching and learning occur in the classroom (Neo \& Neo, 2004). While many students possess at least basic familiarity of the use of ICT, the teacher has an important role to play in developing lessons that enable students to use ICT as a tool to accomplish specific learning goals (Neo \& Neo, 2004). The conjunction of constructivist teaching and ICT integration has the potential to create a more effective learning experience for students (Neo \& Neo, 2004). Schrand (2008) indicates the importance of using ICT to increase the activity level of students in their learning. Chen and Chang (2006) also identify the importance of utilizing technology in conjunction with an educational environment that encourages student activity and exploration. Doolittle and Hicks (2003) assert in their research that the use of constructivism in conjunction with ICT provides an effective opportunity for students to investigate their role as a citizen and demonstrate meaningful learning. Englert, et. al. (2004) also identify the ability of technology to provide scaffolds for thinking and learning in the best practice classroom. Technology has the potential to serve in the role of keeping a student within their zone of proximal development (ZPD) when completing learning tasks in a constructivist classroom (Gentry, 2008).

Despite all of the promises of the joining of ICT with constructivist pedagogy, critics remind us of the reality surrounding the integration of ICT alongside constructivism. Peck, Cuban, and Kirkpatrick (2002) identify the following unrealized promises: technology literacy for all students, improved resources and academic achievement, and a reformed educational system. In addition, some researchers are 
unsure that adequate research has been done to prove that change is even desirable (Kazanci \& Okan, 2009; Okan, 2007). It is important to inspect what constructivism is and in what ways research supports constructivism as best practice pedagogy.

\section{Constructivism}

Constructivism is an important trend in education with regard to the relationships between the actions of teachers and students in the classroom and is often the basis for current educational reforms (Lunenberg, 1998). Though it is often touted as a new way to reform the educational system in the United States, teacher-centered (traditional) pedagogy and student-centered (constructivist) pedagogy have both helped to develop instruction in U.S. schools. Still, constructivism is recognized as the most current learning theory in educational psychology (Ayas, 2006). The ultimate goal of developing best-practice pedagogy is to help students become successful learners and citizens; however, these diverse pedagogies have different ideas about how to best accomplish these goals (Cuban, 2006).

Prensky (2008) explains the difference between traditionalist and constructivist teaching by identifying them as old and new teaching paradigms. He identifies the basic tenant of traditionalist teaching as teachers dispensing knowledge to kids, and the basic tenant of constructivist teaching as teachers providing guidance as kids teach themselves (Prensky, 2008). Prensky agrees that the primary goal of education is equipping students for success, and identifies constructivism as a new way to reach that goal.

Lim and Chai (2008) explain that pedagogical beliefs are, simply put, beliefs about teaching and learning, and further identify that these beliefs have significant implications for effective learning in all environments. In their study on the use of 
constructivism in classrooms, Lim and Chai identified that constructivist principles were most commonly apparent in the categories of lesson type and student role, while more traditionalist principles were common in the categories of teaching style, curriculum, goals, and assessments. Becker and Ravitz (2000) explain that constructivist pedagogy is developed from the educational theories of Dewey, Piaget, and Vygotsky and may include practices like the following:

- activities/curriculum driven by student interests

- collaborative projects that include authentic use of skills

- content centered on complex ideas instead of facts or definitions

- encourage self-assessment

- teachers frequently learn alongside and even from their students

Additionally, Becker and Ravitz (2000) identify four categories that contain both traditional and constructivist poles with regard to teacher beliefs and practices: student tasks, curriculum structure, teaching style, teacher perceptions. A strong emphasis of constructivism is authentic task problem-solving (Häkkinen, 2002). Teachers provide authentic questions or problems that activate learning, aid students in accessing prior knowledge, and provide support for students as they make inquiries and choices (Häkkinen, 2002). Within the constructivist paradigm, it has been said that teachers move from 'sage on the stage' to 'guide on the side' (Mainka, 2007). A key role of the teacher is in instructional design (Häkkinen, 2002). 
Within the tenants of constructivism, teachers create an educational environment that values critical thinking, discussion, cooperation, and inquiry, and students are responsible for their learning within that environment (Lunenberg, 1998). With constructivism the emphasis is on the student learning how to identify and develop their ideas (Lunenberg, 1998). Lunenberg lists five principles of constructivist pedagogy: relevant problems, primary concepts, encouraging students to share their perspectives, student-driven curriculum adaptations, and authentic assessments. Objectives in the constructivist classroom would involve encouraging students to classify, analyze, predict, and create; and encourage students to elaborate on their understanding of various topics constructing relationships and metaphors (Lunenberg, 1998). Additionally, student responses and questions would drive the lesson with the end goal of teaching students to become problem finders and solvers (Lunenberg, 1998). Learning in a constructivist classroom is fluid and active within social situations and frequently follows veins not written into traditional curriculum models (Doolittle \& Hicks, 2003). Constructivism operates on the assumption that students will actively seek knowledge and are innately curious; therefore, motivation would play a key role in the constructivist classroom (Ayas, 2006; Simpson \& Clem, 2008).

According to Doolittle and Hicks (2003), constructivism in general focuses on the role of the student as active participant in their learning, but can be further divided into three branches: radical constructivism, social constructivism, and cognitive constructivism. Radical constructivism emphasizes internal learning, and builds upon the belief that reality outside of the individual cannot be known (Doolittle \& Hicks, 2003). Social constructivism focuses on the construction of knowledge within social 
collaboration, but also holds to the belief that external knowledge is unknowable (Doolittle \& Hicks, 2003). Cognitive constructivism is a conservative form of constructivism that acknowledges external realities that can be explored and understood, thus it involves a search for knowledge in how the world works and knowledge is valuable based on its alignment with reality (Doolittle \& Hicks, 2003). Doolittle and Hicks would hold to the worldview of cognitive constructivism and outline the basic principles of constructivism as follows:

- Constructing knowledge through social and individual processes

- Constructing knowledge within cultural contexts

- Constructing knowledge in authentic, real-world environments

- Constructing knowledge on the foundation of prior knowledge and experiences

- Constructing knowledge within an integration of various subject contexts

- Constructing self-regulation strategies to assess personal learning

It is important to remember that teachers do not necessarily staunchly maintain the same pedagogical style across years or even lessons (Becker \& Ravitz, 2000). External pressures also impact a teacher's pedagogical style and develop their pedagogical beliefs (Becker \& Ravitz, 2000). Cuban (2006) demonstrates in his research on classroom instruction that teachers' pedagogical practices are often hybrids, 
containing tenants of both teaching traditions. Cuban goes on to explain that it is prudent to view the pedagogical practices of teachers along a continuum rather than black and white, but did acknowledge that these hybrid pedagogies are most common in elementary classrooms. Cuban also identifies the role that external pressures play on the beliefs and practices of teachers.

Included in these external pressures is the push to develop pedagogical skills that adequately meet the needs of learners in the Information Age. Simpson and Clem (2008) believe that it is important to determine whether or not the current pedagogy of teachers is sufficient for today's digital learners. They recognize the valuable store of knowledge that teachers hold, but believe that they require more up-to-date pedagogical skills in order to aid students in developing their own knowledge base (Simpson \& Clem, 2008). The research of Neo (2005) does support that today's students prefer the authentic, collaborative problem-solving of constructivist learning.

There is agreement among many researchers that constructivism is the best pedagogical model for the Information Age (Chaptal, 2002). Chaptal does caution that the external pressure of high-stakes testing could discourage teachers from adopting constructivist practices. Similar to the research previously cited, Chaptal identifies the tenants of constructivism as follows:

- complex and realistic problems

- collaborative problem solving

- examining problems from multiple perspectives

- $\quad$ student-ownership of their own learning

- $\quad$ self-awareness and self-assessment 
Countries around the world are including the push for constructivist teaching in many of their educational initiatives, with the hope of helping students develop creativity and problem-solving skills necessary for effectiveness in the twenty-first century (Neo, 2005). These policy makers believe, and are supported by the research, that constructivism offers the greatest promise for improving the education of all students (Lunenberg, 1998) and for increasing the effective integration of ICT in the classroom (Gordon \& Still, 2007). Choi, et. al. (2008) identify that knowledge constructed in authentic environments promoted by constructivism is more active. Hopson, et. al. (2001-2002) explain that the learner in a constructivist environment learns more because their interactions with the material are more authentic, interdisciplinary, and self-driven. They also identify that higher-order thinking skills are more developed in a constructivist environment because students become active participants in their knowledge construction unlike the passivity of traditional classrooms, the focus is on inquiry and big concepts rather than fact regurgitation, there is collaboration with peers, and assessments require the use of higher-order skills rather than fact and definition recall (Hopson, et. al., 20012002).

In their research on the use of video simulations in a constructivist classroom, Simpson and Clem (2008) observed the following results from the constructivist pedagogical approach involved in this classroom: increased classroom and student morale, student ownership of educational tasks, and unique responsibilities within working groups. Keengwe, et. al. (2008b) also recorded that students using technology within constructivist classroom settings scored significantly higher on assessments than those who used technology in traditional classrooms. Additional research suggests that 
the benefits of constructivism lie in the motivation for students and the development of life-long learning skills and explains that constructivist learning encourages the active, authentic problem solving necessary for concept development and essential for lifelong success and learning (Järvelä, et. al., 2008). Additionally, Boling and Beatty (2010) suggest that constructivist environments provide the opportunity for increased formative assessment, which is more conducive to knowledge development than the summative assessment most commonly used in traditional classrooms.

The results of Keengwe, et. al. (2008b) suggest that it is important for teachers to encourage students to construct knowledge through problem-solving, decision-making, and goal-setting because it allows students develop a better understanding of key concepts. Admittedly constructivism can be difficult to implement, and certainly changing from traditionalist pedagogy to constructivist pedagogy would require significant philosophical reevaluation and investment of time, but research suggests that the ends would justify the means (Keengwe, et. al., 2008b). Finally, many believe that constructivism holds the key to the most effective integration of ICT in the classroom (Lunenberg, 1998).

Though it is difficult to discern which is the cause and which is the effect, a strong positive correlation exists between constructivism and ICT integration in classrooms. Some researchers believe that ICT offers the best tool for supporting constructivist learning and identify that the explosive combination of constructivism and ICT integration increases student engagement and motivation (Järvelä, et. al., 2008). Järvelä, et. al. (2008) believe that the scaffolding provided by ICT and the empowerment provided by self-regulation and encouragement of inquiry reduce student uncertainty and 
help guide learning. Scaffolding is important in constructivist pedagogy and involves teachers, or in some cases technology, providing necessary assists to keep students within their zone of proximal development and gradually removing these assists, or scaffolds, as students master necessary skills (Englert, et. al., 2004).

Keengwe, et. al. (2008b) identify that teachers should utilize ICT as a tool within a classroom based on constructivist pedagogy and acknowledge that ICT alone will not change education, but rather the effective use of that technology to increase learning in core subject areas, and identify that teacher pedagogical beliefs are one of several factors involved in the effective integration of ICT in the classroom. Teachers need to know how to effectively use ICT in their classrooms (Ayas, 2006). Ayas also claims that ICT integration is necessary for preparing twenty-first century students and should be used within the paradigm of constructivism.

Hopson, et. al. (2001-2002) identified in their research that teachers felt that ICT classrooms differed from traditional classrooms because learning was student-centered, cooperative groups were used, and learning focused on application allowing students to move past learning facts to applying information to authentic problem solving. Simpson and Clem (2008) stated that the combination of ICT and constructivism in their study led to increased student motivation and active engagement in the learning task. Neo (2005) suggests that the shift toward constructivist pedagogy has opened up opportunities for the integration of ICT in the classroom. Butzin (2002) supports this claim, identifying that the greatest hindrance to effective ICT integration is the attempt to integrate ICT into traditionalist pedagogy, and that constructivism creates greater opportunity for effective ICT integration. 
Mueller, et. al. (2008) suggest that constructivist pedagogical beliefs may be a prerequisite for effective technology integration. Chaptal (2002) explains that technology can be used to support both traditional and constructivist pedagogy, but that it is most effective when used alongside a constructivist model of teaching and learning. Prensky (2008) agrees that it is combination of ICT integration and constructivist pedagogy that holds the key to educational reform that prepares students for the twenty-first century. Ayas (2006) also identifies that ICT is well-suited for use as a tool in a constructivist classroom and that constructivist values are supported by the use of ICT in the classroom to provide students with a tool that enhances their motivation, collaboration, and ownership of classroom activities. Doolittle and Hicks (2003) support these claims, identify this transformation of education as essential, and offer the following suggestions for constructivist-based ICT integration in the classroom:

- Implement technology as a tool for inquiry

- Implement technology as a way to increase taskauthenticity

- Implement technology that increases social interaction on all levels

- Implement technology to provide effective feedback

- Implement technology to encourage student independence

Becker and Ravitz (2000) caution that there are many ways to build a classroom based on constructivist pedagogy, but they also recognize the possibilities of ICT when used as a tool to achieve constructivist goals. Research supports the important role of the 
classroom teacher on the effective integration of ICT as a tool to meet the needs of the complex classroom environment (Lim \& Chai, 2008). The research of Becker and Ravitz examined the hypothesis that continued ICT use in the classroom would lead to changes in pedagogy toward constructivism. Their results supported the hypothesis that teachers who regularly integrated ICT into their classroom activities also reported the greatest shift in their personal pedagogies toward constructivism. Becker and Ravitz suggested the following explanations for this correlation:

- These teachers learn over time that they are more effective when using constructivist teaching strategies.

- These teachers may have already held philosophical beliefs bent toward constructivism

- These teachers may have been influenced by an external culture that supported both ICT integration and constructivism

- These teachers were the most willing to experiment with their teaching style and took a more innovative approach toward education pedagogy and ICT use in the classroom

Scardamalia and Bereiter (2008) remind that ICT is a tool and therefore it is dependent upon the work of teachers for its effective use. In their work on the use of simulations in the classroom, Adams, et. al. (2008) identify that the simulations were optimally effective when their use was student-driven, allowing students to formulate their own questions and actively seek answers. Similarly, Hermans, et. al. (2008), 
identify that when considering effective ICT integration it is imperative that stake holders consider the myriad of factors involved, including the teacher's pedagogical beliefs. Their work established that constructivist teacher beliefs were a strong predictor of ICT integration in the classroom (Hermans, et. al., 2008). Culp, et. al. (2005) concede the promise of technology as an catalyst to encourage constructivist pedagogy, but caution that adequate professional development is essential to realizing the combined power of constructivist pedagogy and ICT integration.

\section{Current Utilization of ICT}

Significant investments in technology have led to questions about its impact on teaching and learning (Bebell, et. al., 2004). Key leaders in the field of ICT integration, including both cheerleaders and skeptics, have started to question whether or not the significant investments in ICT are justified by the results of their use (Chaptal, 2002). Cuban (2000), for example, feels that there is little evidence to support continued investments in ICT technologies and even questions the necessity of ICT skills for future careers. Many researchers, including Keengwe (2007) cite the work of Cuban as identifying and explaining the failure to effectively integrate ICT in instruction despite significant expenditures on ICT technologies. Carnevale (2004) also indicates a failure of the acquisition of ICT to create meaningful change.

The research of the National Education Association indicates that progress has been made in the area of ICT integration in the classroom, but there are still many obstacles to widespread use (Tuck, 2004). One conclusion of the NEA report was that students need greater meaningful access to computers in the classroom (Tuck, 2004). The reality is that greater access and availability has been established, but widespread 
utilization of ICT in the classroom has not yet been attained (Chaptal, 2002). This suggests that stakeholders must now shift their focus to investing in the people who will use the ICT infrastructure that has been built through previous investments (Keengwe, 2007).

In their investigation of ICT use in high schools of Silicon Valley, Peck, et. al. (2002) identified that the use of ICT in classrooms other than computer-based electives was limited. Many of the students indicated that they never used computers, and researchers found significant discrepancies within departments (Peck, et. al., 2002). Additionally, the students who did report computer use, including those in computerbased electives, identified that the use was teacher-driven, and researchers reported that they found little evidence of the constructivist learning that ICT supporters promote (Peck, et. al., 2002). This research supports the theory that just providing the ICT equipment is not enough to enable teachers to effectively integrate ICT in their classrooms (Keengwe, Onchwari, \& Wachira, 2008a).

When exploring the effects and pervasiveness of technology in the classroom, researchers must move beyond the existence of ICT in the classroom and attempt to understand its role and usage in the cultural context of the classroom with specific reference to students and teachers (Bebell, et. al., 2004; Kurt, 2010). With regard to teachers, the all-encompassing phrase 'technology use' is not clear enough to provide real benefit to researchers (Bebell, et. al., 2004). Originally researchers used this phrase in order to simplify their research, but this has caused problems for researchers including: a lack of a valid measure, interpretation of findings, and identifying ways to increase ICT use in the classroom (Bebell, et. al., 2004). Bebell, et. al. identify that it is important to 
identify the individual categories of ICT use, because they have a weak enough relationship to do so, and these categories can provide us with a deeper understanding of ICT use in the classroom.

Evidence suggests that a great number of teachers are currently using technology to support their own teaching, record keeping, worksheet and test development, and tracking of student progress (Bebell, et. al., 2004; Kurt, 2010). Van Braak, Tondeur, and Valke (2004) identify that a majority of teachers use ICT to support their teaching, but far fewer integrate ICT into their instructional repertoire. By the beginning of this millennium, over $85 \%$ of teachers used their computers for the creation of instructional materials, and over $50 \%$ of teachers used their computers for record-keeping and administrative tasks (Bebell, et. al., 2004). Through their research, Bebell, et. al. examined through survey responses the specific activities that teachers utilized their computers for and developed the following list of categorical activities: preparation, professional e-mail communication, delivering instruction, accommodation, teacherdirected student use, teacher-directed student products, and grading. Bebell, et. al. tested the assumption that these measures would all be related to each other and found only weak to moderate relationships.

Bebell, et. al. (2004) also compared technology use to length of time in the field of education and found no noticeable variance in teacher use. Comparisons of technology use and level taught identified only slight differences, including increased use for accommodation at the elementary level and increased use for preparation at the middle and high school levels (Bebell, et. al., 2004). Kurt (2010) also explains that when technology is used in the classroom, it is frequently used to maintain traditional 
pedagogy, rather than developing activities that align with constructivist pedagogical methods. Teachers primarily utilized ICT for instruction in how to use ICT, administrative activities, instructional purposes that aligned with previously held pedagogical beliefs, and non-educational tasks (Kurt, 2010).

The National Education Association conducted a survey to investigate the effective use of ICT in the classroom (Tuck, 2004). The major findings of this survey included:

- Most educators had access, but student access was limited.

- Educators were involved in decision making, but upgrades and support were limited.

- Educator training was inadequate to support integration in instruction.

- Gaps in technology access remained for certain demographic groups.

- Some educator attitudes were maintained over time, but some changed or became increasingly complex.

Ferneding (2003) suggests that the job skills required for success in the Information Age are a significant part of the push for the use of ICT in education. Casey (2008) questions why schools are not playing a more significant role in preparing their students for ICT use in their futures. Given the pervasiveness of technology in the Information Age and the significant investments that have already been made toward ICT programs in schools, it seems inevitable that ICT will continue to have a role in 
classrooms (Chaptal, 2002). The question that remains is what that role will be and what those classrooms will look like. The National Education Association gave the following recommendations (Tuck, 2004):

- Make computers available in the classrooms that provide regular access throughout the school day.

- Provide adequate staff development, equipment upgrades, and technical support to encourage broadscale integration.

- Include the staff in decision-making about all areas of school technology, including training and professional development opportunities.

- Ensure that pre-service and in-service teachers are adequately prepared to integrate technology in their classrooms.

- Close disparities between demographic groups.

- Upgrade and maintain equipment in impoverished school districts.

- Encourage further research and development of technology programs.

Ertmer and Ottenbreit-Leftwich (2010) claim that low-level ICT use is no longer appropriate for students. With the advent of the twenty-first century, teachers should be expected to use technology for effective constructivist teaching, and technology should no longer be viewed as a supplemental tool for teaching, but rather an essential tool for 
effective teaching (Ertmer \& Ottenbreit-Leftwich, 2010). Thus, technology skills and training in technology integration would be requirements for the twenty-first century teacher. Scardamalia and Bereiter (2008) do caution the pitfall of allowing product focus to limit the content knowledge acquisition when learning with ICT, but agree that technology can support constructivist values, when used appropriately. Again, this illustrates the need for proper training and skill development in the twenty-first century teacher. Important to note is that the majority of teachers do believe that computers are effective and important educational tools (Silman \& Gündoğdu, 2007), they just need to be equipped to use them in their classrooms.

The promises of ICT integration were explained in detail in a previous section of this chapter, and a failure to realize some of those promises questions whether or not students are being provided with the best possible education. Keengwe, et. al. (2008b) recorded increased achievement for students who utilized ICT in conjunction with constructivist practices when compared to students using ICT with traditional practices. ICT integration and constructivist pedagogy are two sides of the same coin that may provide the key to increased student learning and success. Schrand (2008) observed increased authenticity in student participation when utilizing interactive multimedia to create active-learning exercises. Isolated examples of effective integration abound; now the goal is to create a more wide-spread phenomenon.

Authorities frequently play the blame game and identify teachers as the root of the problem of limited ICT integration, but others have also suggested attitudes that include: failure to prove ICT's efficiency to individuals, school designs and cultures that don't promote the widespread use of technology, and the need for greater patience when 
waiting for widespread integration to occur (Chaptal, 2002). Peck, et. al. (2002) also identify that teachers often take the blame for the lack of technology use, but identify that other challenges hinder the use of technology in schools including: school and classroom structures, time constraints, defects in the technology, and competing priorities.

While teachers do determine what activities will occur in their individual classrooms, one must recognize that teachers receive significant pressures from various stake holders in the field of education, thus change will likely be progressive and require support and professional development (Chaptal, 2002). Zhao, Hueyshan Tan, and Mishra (2000-2001) also suggest that ICT integration combined with pedagogical changes create a great deal of uncertainty and that uncertainty leads to slow and cautious changes. Kromhout \& Butzin (1993) indicate from their study on ICT integration with project CHILD that one of the greatest concerns is the workload required of teachers. Kurt (2010) identifies at the conclusion of his research that teachers cannot be forced to integrate ICT into their curriculums, but programs can be developed to guide teachers in the importance and appropriate use of ICT in the classroom. The National Education Association study on ICT use in schools, found that staff training on technology use was increasing, but there was a lack of time and opportunities to learn about the instructional uses of these technologies (Tuck, 2004).

With regard to school designs and cultures, Chaptal (2002) suggests that schools should change to encourage constructivist teaching practices, but cautions that traditional testing may thwart efforts to further develop and implement constructivist teaching alongside ICT use. Kromhout \& Butzin (1993) also indicate that standardized tests cannot adequately assess the learning in ICT enriched, constructivist classrooms. Cuban 
(1994) believes that schools are different from other organizations, and these differences hinder the wide-scale integration of ICT into the classroom. According to Cuban, these differences include: beliefs about teaching and learning, what constitutes proper content, views on the teacher-student relationship, age-grade classroom divisions, equitability, and instructional organization.

Another struggle in the effective integration of ICT in schools is the varied skill levels of students with regard to ICT, prompting researchers to identify that there is still a need for some direct instruction in ICT skills for students (Keengwe, 2007; KarchmerKlein, 2007). This is not to say that ICT should not be integrated into the curriculum as that is where it is most effectively used, only that direct ICT instruction for students should continue to be a part of a comprehensive technology plan.

Keengwe, et. al. (2008a) conclude that there are many factors that influence ICT integration, including access, support, and training. They explain that ICT integration alongside pedagogical reform requires major changes in education and teaching practices, thus reformers should move forward with caution, recognizing the need for incremental changes (Keengwe, et. al., 2008a). Van Braak, et. al. (2004) explain that past experience and behavior have a significant impact on teacher decisions to integrate ICT into their classroom. Keengwe, et. al. offer the following as obstacles to effective ICT integration: lack of computers, limited quality of software, time constraints, lack of funds, technical problems, teacher attitudes toward computers, lack of teacher confidence, resistance to change, lack of administrative support, lack of training, in addition to the challenge of behavior and commitment of individual teachers. 
Buckenmeyer (2010) maintains that the challenge of getting the technology into the classrooms is being met in many schools and the focus must now be shifted toward utilizing that technology. Okan (2007) cautions that it is prudent to develop a complete picture of the myriad of factors involved before making judgments or instituting changes with regard to ICT integration.

\section{Integration}

Researchers would agree that ICT provides additional educational opportunities when it is used effectively (Keengwe, et. al., 2008b). Currently, whether or not to use ICT is rarely questioned, rather the question focuses on what constitutes effective use (Valanides \& Angeli, 2008). While there is a need for some direct instruction (Keengwe, 2007), the true promise of ICT lies in its integration into the content areas. In fact, many researchers, including Keengwe, et. al. use the effective integration of technology as a measure of technology's success and usefulness in schools. For the most part, the necessity of integrating technology into the basic curriculum, rather than offering it as external elective courses, has been established and is now assumed (Keengwe \& Anyanwu, 2007; U.S. Department of Education, 2004). Additionally, most researchers admit that the substantial investments that have been made in ICT, will only be considered money, and time, well spent when teachers are able to make wise decisions about the effective use of ICT in the classroom to incorporate active and authentic learning opportunities into the daily curriculum (Pasco \& Adcock, 2007).

Curriculum standards from both national and state organizations require or recommend the integration of technology in the classroom (Polly \& Hannafin, 2010; Fletcher, 2006). Fletcher also indicates that it is only through the integration of ICT that 
these technologies will be utilized in a way that students receive the best possible education for their future success in an increasingly technological world. Teachers are now facing classrooms of technology savvy students who are well entrenched in the Information Age, but still require teaching to understand the effective use of ICT for learning (Keengwe \& Anyanwu, 2007). From the perspective of these digital natives it is expected that their educational experience will include the use of ICT for learning. Tearle (2003) identifies that the invasiveness of ICT on the various sectors of society indicate that it will have some place in education and acknowledges the oft-touted promises of ICT integration in the classroom. It is expected that eventually teachers of all levels will be required to integrate technology into their teaching (Joshi, et. al., 2010).

Keengwe, et. al. (2008a) state that evidence demonstrates a lack of widespread integration in schools and recognize that ICT provides both challenges and opportunities for classroom teachers. Keengwe, et. al. (2008a) suggest that teachers work to meet several objectives in relation to ICT integration in the classroom: incorporate active learning and teaching, develop appreciation for technology, become leaders of effective integration, design curriculum activities that incorporate ICT, recognize the power of ICT integration, understand the benefits of ICT in the classroom, learn to motivate students using ICT, and become advocates for ICT integration in the classroom. Technology should be used in the classroom with the purpose of improving student learning of curriculum materials, and teachers should focus on developing meaningful learning experiences that incorporate technology as a means of creating learning opportunities for their students (Keengwe, et. al., 2008b). Prensky (2008) also identifies that ICT integration allows teachers to achieve constructivist teaching goals more efficiently and 
effectively when used properly in the classroom. Project CHILD also offers evidence to support claims of effectiveness in regard to ICT integration in the classroom (Butzin, 2000).

Many research studies have established that ICT presence alone does not assume effective use. Rather careful design and implementation of activities in which ICT components are used to effectively participate in authentic learning experiences is required in order to effectively enhance learning (Delialioglu \& Yildirim, 2008). Cady and Terrell (2007-2008) completed a study on the effect of ICT integration on female students and determined that ICT integration had a significantly positive effect on the attitudes of female students toward computer importance. Harris, et. al. (2009) identified the importance of developing lessons in which technology and content work together to create effective learning experiences and indicated that effective teaching required the understanding of content and effective strategies to aid students in learning that content. Though researchers have established the necessity and effectiveness of ICT integration in the classroom, many also recognize that widespread integration has not yet occurred (Razfar, 2008).

Understanding the importance of integration does not necessarily lead to experiencing the reality of teaching and learning in a classroom augmented by ICT integration. Stake holders initially believed that providing the hardware and infrastructure would lead to effective integration of ICT into classrooms, but most now realize that more is required (Culp, et. al., 2005; Tondeur, et. al., 2009). Researchers have now begun to investigate the complex combination of factors involved in effective ICT integration. In addition to physical availability of ICT infrastructure, accessibility is 
a reference to appropriateness compared to content, support, training, and ability to use effectively (Culp, et. al., 2005). Additionally, identifying and defining long-term goals can be hindered by several interacting factors including: multiple types of technologies, rapid creation and upgrading of technologies, working and fluctuating budgets, and public perceptions (Culp, et. al., 2005).

Current approaches to ICT integration fail to recognize the complex dynamics involved in integration (Harris, et. al., 2009). Techno-centric approaches to ICT integration have fallen flat due to their failure to consider the content and pedagogical factors involved in effective integration (Harris, et. al., 2009). Many conventional approaches focus on the ICT components and ignore the learning needs of prospective students (Harris, et. al., 2009). Harris, et. al. point out in their work that it is imperative to consider technology, pedagogy, content, and background knowledge when developing activities that involve ICT integration. Still, as if to further illustrate the complexity of ICT integration, each of these areas has a complex set of factors of its own.

Keengwe and Anyanwu (2007) further explain that ICT integration is a complex phenomenon that involves teacher interactions, teacher beliefs, and teacher attitudes. Tondeur, Valke, and Van Braak (2008) attempted to identify the factors that influence ICT integration, but questioned whether or not a complete list of the complex factors and their interactions was even possible to create. In their work on developing an inventory for assessing ICT integration, Groff and Mouza (2008) also identify the complexity and challenges of effective ICT integration. Yet, Levin and Wadmany (2008) explain that it is important to understand as much as possible about the complex dynamics involved in ICT integration in order to increase effective integration. Also of note is that some of the 
factors, including teacher beliefs and attitudes, exist on a continually shifting continuum which creates more complex dynamics, and it is important to avoid developing an approach to ICT integration that maintains a one-size-fits-all mentality (Levin \& Wadmany, 2008).

ICT integration involves a variety of factors, continually changing and interacting over-time, creating difficulty for researchers, teachers, and policymakers interested in studying the effective integration of ICT in classrooms (Tondeur, et. al., 2009). This difficulty can sometimes hinder ICT integration because it creates an atmosphere of adventure and innovativeness that is also plagued with uncertainty (Chaptal, 2002). This uncertainty can sometimes lead to reticence on the part of administrators and teachers implementing ICT in their schools and classrooms. Perhaps most importantly, effective ICT integration can require major changes and reevaluations of personal beliefs, attitudes, skills, and actions (Keengwe, et. al., 2008a)

Based on the combined work of many researchers (Baek, 2008; Fletcher, 2006; Groff \& Mouza, 2008; Joshi, et. al., 2010; Keengwe, et. al., 2008a; Keengwe, et. al., 2008b; Klieger, Ben-Hur, \& Bar-Yossef, 2010; Levin \& Wadmany, 2008; Loveless, 1996; Maynard, 2010; Pasco \& Adcock, 2007; Razfar, 2008; Russell, et. al., 2003; Shepherd \& Mullane, 2010; Steketee, 2005; Tearle, 2003; Thomas \& Vela, 2003; Tondeur, et. al., 2008; Tondeur, et. al., 2009; Valanides \& Angeli, 2008; Van Braak, Tondeur, Valcke, 2004; Wright \& Lesisko, 2008; Wright, 1996; Yaghi \& Ghaith, 2002; U.S. Department of Education, 2004), the following list of factors involved in ICT integration has been developed. It is important to remember that many complex interactions of these factors exist beyond the straightforward list given here: 
- Motivation of teachers

- Perceptions of teachers

- Pedagogical beliefs of teachers

- Teacher beliefs about technology

- Interrelationships between factors

- Teacher attitudes toward ICT use and integration

- Teacher attitudes toward creativity and innovativeness

- Organizational factors

- Time constraints

- Availability of and access to resources

- Level of support available

- Teacher attitudes toward constructivism

- Cultural and structural characteristics of the school

- Teacher training and professional development

- Leadership that promotes change and supports teachers

- Focus, goals, and implementation of school vision

- Supportive interaction between colleagues

- Practice and success with ICT integration in the classroom

- Lack of technological skills

- Ability to utilize available technology for educational purposes

- Student attitudes and abilities 
- Reliability of available technology

- Teacher anxiety with regard to computer use

- Teacher beliefs about age appropriateness of computers

- Control and assessment concerns

- Budgetary constraints

- Practical implementation of skills gained during ICT training

Groff and Mouza (2008) divide these factors into six categories: legislative factors, district/school level factors, teacher factors, ICT project factors, student factors, and inherent technology factors. Of these factors, teacher beliefs are the strongest factors in ICT integration (Russell, et. al., 2003). The integral role of the teacher in ICT integration and the factors related to the teacher will be examined further in the next section.

Legislative factors, inherent technology factors, and school factors represent the groups that individual teachers have the least, if any, amount of control over (Tondeur, et. al., 2009). Legislative factors include government policy and available research (Tondeur, et. al., 2009). District and school level factors include structural and cultural school factors (Tondeur, et. al., 2009). Though these factors are difficult to define, research has determined that these factors are related to the way that stakeholders perceive, think, and feel about various aspects of school and include staff attitudes toward innovativeness, school vision, and supportive leadership (Tondeur, et. al., 2009). Constructivist teaching beliefs is believed to be the most influential cultural factor to ICT integration (Tondeur, et. al., 2008). School factors can also include age of the school 
buildings, availability of technological staff, budgetary considerations, and teacher training program availability (Tearle, 2003).

Integral Role of the Teacher

Levin and Wadmany (2008) identify that teachers play the key role in changing the field of education, especially the way teaching and learning occur in their individual classrooms. In his research, Loveless (1996) explains that a significant hindrance to effective classroom integration lies in the failure to recognize the integral role of the classroom teacher. Karchmer-Klein (2007) identifies the classroom teacher as the most important factor to classroom integration, but continues by explaining that they are not trained properly to effectively integrate ICT into their classroom teaching. Casey (2008) suggests that given the continued divergence of expert opinions, the greatest hope for educational reform and effective ICT integration is talented teachers making informed decisions about how to utilize ICT in their classroom. One thing is certain- teachers face numerable obstacles and important decisions in how to effectively use ICT in their classrooms (Silman \& Gündoğdu, 2007). Kurt (2010) also identifies that successful integration is largely contingent on the classroom teacher. Gall and Breeze (2008) identified in their study that effective integration that fosters collaboration in a positive learning environment was contingent on the classroom teacher.

With this understanding of the important role of the classroom teacher, it is easy to fall into the trap of blaming teachers, thus using them as scapegoats, for the failure to realize the promises of ICT integration in the classroom (Ferneding, 2003; Cuban, 1999a). Though some researchers would decry the injustice of this action and revert to turning ICT and policy makers into the scapegoats (Ferneding, 2003) and others, as 
demonstrated previously in this chapter, would continue to lift up the promises and provision of ICT components and infrastructure despite the failure of teachers to integrate ICT in the classroom; as with most things, the truth probably lies somewhere in between. Emergent ICT is not a "magic bullet" that can single-handedly reform and enhance the educational system in the United States, but rather is dependent upon the valuable insight of well-trained teachers to fully integrate and realize its potential (Casey, 2010).

Additionally, teachers are not equipped, empowered, or trained to effectively navigate all the factors involved in ICT integration (Hixon \& Buckenmeyer, 2009).

Shepherd and Mullane (2010) draw attention to the fact that teachers are failing to integrate technology into the classroom and cite maintenance costs, lack of training, and ineffective preparation for technology use in the classroom setting as possible obstacles. In their study on the past two decades of governmental policy on ICT use in classrooms, Culp, et. al. (2005) assert that these reports identify high quality, sustained professional development as essential to effective ICT integration. Additionally, it is imperative that teachers are willing to experiment with various technologies and activities as they are attempting to effectively incorporate ICT into their teaching repertoire (Buckenmeyer, 2010).

Many researchers have identified various factors involved in ICT integration that are directly linked to teachers. Some of these factors include: positive experiences, comfort with computers, beliefs about computers as an instructional tool, level of training, motivation and innovativeness, administrative and collegial support, and teaching efficacy (Mueller, et. al., 2008). Hixon and Buckenmeyer (2009) identify the following factors: access does not equal integration, time constraints, lack of training 
and/or appropriate times for training, and lack of technical support. These researcher further divide factors involved in integration into first order barriers, or barriers the teacher cannot control, including lack of resources and school culture; and second-order barriers, or barriers within the teacher's control, including personal beliefs, attitudes, knowledge and skills (Hixon \& Buckenmeyer, 2009). Cuban (1999b) expounds upon first-order barriers, citing contradictory and ever-changing advice from experts, inflexible schedules, outside demands, unreliability of technology, disrespect for teacher opinions, the nature of education, and the multiple purposes or masters that schools serve as additional first-order barriers. Important to note is that the factors of years in the field, gender, and age of the teacher have inconsistent and low impact with regard to effective ICT integration (Mueller, et. al., 2008; Cuban, et. al., 2001). Teacher proficiency with ICT components did have a significant impact on their ability to increase student gains from ICT use in the classroom (Chen \& Chang, 2006).

Using technology just for the sake of using it is not helpful in the classroom, nor does it lead to the realization of the promises of ICT integration in the classroom. Rather, it is the teachers that work to determine the why and how of ICT integration in the classroom who turn promises into reality (Kazanci \& Okan, 2009). The benefits of ICT use in the classroom rely on how the teacher structures the classroom environment and activities while utilizing ICT components (MacBride \& Luehmann, 2008). Callister and Dunne (1993) explain that machines are tools that require the perceptions and decisions of teachers for effective use. Lim and Chai (2008) acknowledge that researchers are finally beginning to recognize the integral role of individual teachers in effective ICT 
integration and the complex environment that these teachers must negotiate in their decision making.

Kurt (2010) asserts that policy-makers, administrators, and proponents of ICT integration expect teachers to integrate ICT into their classroom activities, but most also recognize that the decisions of when and how to accomplish this ultimately lie in the hands of classroom teachers. Classroom teachers have the greatest influence over what happens when the doors to their classrooms close and instruction begins (Groff \& Mouza, 2008). Having an understanding of this identifies the importance of investigating the roles of teachers in ICT integration and investing in professional development for these teachers (Mueller, et. al., 2008). Levin and Wadmany (2008) identify that teachers have the most impact on ICT use in the classroom and explain that realizing the promises of ICT integration is reliant upon how the classroom teachers decide to use ICT in their classrooms. Examining the list of factors involved in ICT integration, research demonstrates that teacher factors have more influence than the other factors when considering ICT use in classrooms (Thomas \& Vela, 2003).

In his critical exposition on computer use in schools, Loveless (1996) suggests that students, parents, and other stake-holders instinctively understand that unhindered computer use in the classroom will increase the personal responsibility of the learner beyond where it should be, and the teacher provides some control and authority over classroom ICT use. Keengwe and Anyanwu (2007) explain that it is ultimately the teacher, not the technology, which will be held accountable for the education of their students. Experience teaches that students need teachers to support them and facilitate their learning (Shepherd \& Mullane, 2010). 
In reference to the blame on teachers for not adequately using ICT technology in the classroom, Loveless (1996) agrees that teachers should develop stronger skills for utilizing ICT in the classroom but reminds readers that teachers are experts at teaching even if they are not experts in ICT. Continued investments in ICT for classrooms combined with research demonstrating continued hindrance of ICT usage in the classroom, puts continued pressure on teachers who are being blamed for the failure of ICT to activate educational reform (Keengwe, et. al., 2008a). Teachers frequently cite lack of time and lack of educational ICT training as barriers to the utilization of ICT in the classroom (Fletcher, 2006). Ruthven, Hennessy, and Deany (2008) also cite the necessity of curriculum selection and adaptation, including negotiating attempts to teacher-proof curriculum, as hindrances to ICT integration. Research demonstrates that computer training increased innovativeness and use for support and integration (Van Braak, et. al., 2004).

Of the teacher factors involved in ICT integration, teacher beliefs and attitudes have the most significant impact on ICT integration in the classroom (Hermans, et. al., 2008; Thomas \& Vela, 2003). Kagan (1992) provides an understanding of the role of teacher beliefs in the classroom. Kagan compares the teaching profession to creative invention and identifies teacher beliefs as internal, implicit, resistant to change, and intensely private. Although teacher beliefs cannot be fully understood from observations of instructional practices, certain activities can provide illumination of an underlying belief system (Kagan, 1992).

One hindrance to understanding belief systems is that various secondary and tertiary beliefs are established based on basic core beliefs that have multiple connections 
to other beliefs and core beliefs are the most difficult to change (Ertmer \& OttenbreitLeftwich, 2010). Another hindrance to understanding teacher beliefs is that teachers are often unable to adequately explain their own unconscious beliefs (Kagan, 1992). In addition to their inability to articulate their specific belief systems, teachers may also lack the ability to fully articulate barriers to ICT use in their classrooms (Hixon \& Buckenmeyer, 2009).

Further complicating the understanding of teacher beliefs are inconsistencies between self-expressed beliefs and observed beliefs in the classroom (Lim \& Chai, 2008). In attempting to explain these discrepancies, teachers once again cited external time, training, and evaluation constraints (Lim \& Chai, 2008; Tuck, 2004). Most professional knowledge can also be considered a part of teacher belief, but current belief acts as a filter for the dissemination and utilization of new knowledge (Kagan, 1992; Ertmer \& Ottenbreit-Leftwich, 2010). Research identifies that changes in belief systems require application of knowledge gained rather than theoretical studying (Kagan, 1992).

Kagan (1992) further divides teacher beliefs into two categories: self-efficacy and content-specific beliefs. Self-efficacy refers to expected ability to perform instructional and professional tasks, and content-specific beliefs refer to understanding and ability regarding specific academic content (Kagan, 1992). Teachers' self-efficacy toward problem-solving skills can have a significant impact on their willingness to experiment with ICT integration in the classroom (Hixon \& Buckenmeyer, 2009; Thomas \& Vela, 2003). Tondeur, et. al. (2008) identify that constructivist pedagogical beliefs are essential to ICT integration. Even if a teacher's pedagogical beliefs are in line with ICT integration, the teacher must believe that she has the technological ability to implement 
activities involving ICT integration (Mueller, et. al., 2008; Loveless, 1996). Yaghi and Ghaith (2002) also support the assertion that confidence related to computer use and, more importantly, computer use for educational purposes (Pasco \& Adcock, 2007) plays a significant role in teacher's deciding to integrate ICT into the classroom.

Teacher belief is significantly influenced by the isolating nature of classroom instruction (Kagan, 1992). The level of control that teachers possess in their classrooms establishes a sense of safety and predictability for teachers, which can sometimes cause teachers to be skeptical or defensive about external advice (Kagan, 1992; Hixon \& Buckenmeyer, 2009). Kagan also describes the uncertainty and ambiguity of classroom tasks and the resulting development of a personal pedagogical belief system that allows the teacher to maintain confidence and certainty in the classroom. Kagan suggests the use of creative expression to limit the isolation factors by providing a connection to others. The resulting collaboration provides opportunities for merging belief systems and further development of school culture (Kagan, 1992).

Levin and Wadmany (2008) also identify the necessity of administrative and collegial support for teachers to develop self-efficacy and effectively integrate ICT in the classroom. One teacher identified the integral role that administrative support played in her decisions to persevere through encountered difficulties, and another teacher identified support from and collaboration with colleagues as the source of her courage and confidence regarding ICT integration (Levin \& Wadmany, 2008).

The utilization of ICT in classrooms causes most teachers to take on a different role in their classroom (Silman \& Gündoğdu, 2007). Despite the fact that the majority of teachers believe that computers are effective tools for teaching and learning and that 
students may need ICT skills post-graduation, conflicting teacher beliefs and pressures still hinder their use in the classroom (Silman \& Gündoğdu, 2007; Chen, 2008). According to Chen and supported by Ertmer and Ottenbreit-Leftwich (2010), the resulting discrepancies lie in the negotiation process teachers go through when determining the most effective tool they are able to use to meet a variety of prioritized learning goals within a specific school culture that may or may not support ICT integration.

The reality exists that many teachers may simply view technology as an unnecessary distraction in an already overbooked schedule (Gordon \& Still, 2007). Prensky (2008) elaborates, indentifying that one reason teachers struggle so much with change is that teachers feel outside pressure to cover all of the curriculum materials they are given. Additionally, teachers are hindered in their decision-making in the classroom by the need to provide a quality education for all of their students by balancing individual student needs with corporate student needs (Ferneding, 2003). Levin and Wadmany (2008) assert that teachers must be willing to learn how to use technology and examine, possibly even change, their foundational pedagogical beliefs in order to realize the benefits of effective ICT integration. Research shows that teachers who possess a willingness to change, try new things, and be innovative in the classroom are more likely to attempt high level ICT integration in the classroom (Hixon \& Buckenmeyer, 2009).

In addition to teacher beliefs, teacher attitudes play a significant role in decisions regarding ICT integration (Van Braak, et. al., 2004; Tondeur, et. al., 2008). Teacher ability to use computers is positively correlated to teacher attitudes toward computers, and teacher attitudes towards computers are significantly linked to computer use in the 
classroom (Van Braak, et. al., 2004; Gordon \& Still, 2007). General innovativeness and familiarity with computers also have a significant impact on teacher attitudes toward computer use in the classroom (Van Braak, et. al., 2004). Desire, training, and support are also significant factors in teacher decisions to integrate ICT into their curriculum (Fletcher, 2006). According to Keengwe, et. al. (2008a, p. 562, II 2) the most significant factors hindering ICT integration are the "behavior, investments, and commitments of individual teachers." Teachers need to be interested, motivated, and willing in order to use ICT meaningfully in the classroom (Keengwe, et. al., 2008b).

In a study conducted by the National Education Association, researchers attempted to analyze ICT integration from the perspectives of classroom teachers (Tuck, 2004). Their research indicated that the attitudes of educators toward technology for educational purposes had a significant impact on successful ICT integration (Tuck, 2004). Training in computer skills had the most significant relationship with computer use and training, and technology enjoyment was strongly related to familiarity with and positive attitudes toward computer use for educational purposes (Tuck, 2004). Time also impacted skill levels, advanced usage, and perceived impact on job performance (Tuck, 2004). Also, teachers were more likely to value technology that improved access to content information or efficiency in product creation (Tuck, 2004).

Past experiences with ICT integration also have a significant impact on a teacher's beliefs and attitudes toward ICT integration (Mueller, et. al., 2008; Tuck, 2004; Baek, 2008). Groff and Mouza (2008) explain that teachers who are continually met with failure when attempting to utilize ICT in their classrooms, are likely to develop negative beliefs and attitudes toward integration. In contrast, teachers who meet success when 
attempting to utilize ICT in the classroom are more will to continue attempting innovative ICT enhanced lessons (Groff \& Mouza, 2008). Groff and Mouza suggest paying attention to the teacher-controlled factors of ICT integration including context, innovator, innovation, and operators when examining successful ICT integration in the classroom. They outline school factors like resources and support; teacher factors like technology proficiency, pedagogical beliefs, and innovativeness; project factors like relationship to school culture, dependence on outside resources, and relationship to current pedagogical practices; and student factors like technology proficiency, attitudes, beliefs, and engagement as important to predicting success with regard to activities involving ICT integration (Groff \& Mouza, 2008). Their research supports teacher training in technology skills, the importance of positive teacher beliefs and attitudes, the influence of pedagogical beliefs, and the importance of successful experiences with integration for future attempts at ICT integration (Groff \& Mouza, 2008). Availability and access to support is of utmost importance (Groff \& Mouza, 2008).

Although research has established the potential of ICT integration in classroom, it also shows that many teachers are not yet prepared to effectively integrate ICT into their classrooms (Chen \& Chang, 2006). Though observers once believed that veteran teachers and digital immigrants would have the most trouble making the shift to ICT enhanced classrooms, research now demonstrates that novice teachers have more difficulty with this step (Chen \& Chang, 2006). It is important to remember that teachers most often take on the pedagogical styles of the teaching they have experienced; and, although undergraduate educational programs can have some impact on pedagogical beliefs, practically speaking, pre-service teachers generally leave their undergraduate 
programs with the same pedagogical beliefs that they started them with (Ertmer \& Ottenbreit-Leftwich, 2010; Kagan, 1992), creating novice teachers with traditional pedagogical belief systems despite their familiarity with technology. Additionally, the research of Guo, Dobson, and Petrina (2008) also suggests that the differences between digital natives and digital immigrants have been exaggerated.

Hixon and Buckenmeyer (2009) explained that teachers progress through various stages with regard to reaching the goal of best-practice ICT integration in the classroom. While various researchers give these stages different names, there is sufficient evidence to suggest that teachers move through stages involving specific characteristics (Hixon \& Buckenmeyer, 2009; Groff \& Mouza, 2008). The first stage involves the development of basic ICT skills (Hixon \& Buckenmeyer, 2009). The second stage contains the utilization of ICT skills to increase professional efficiency (Hixon \& Buckenmeyer, 2009). During the third stage, teachers begin to utilize ICT in the classroom for delivery of instruction that maintains existing pedagogical practices (Hixon \& Buckenmeyer, 2009). Next, teachers begin to experiment with best-practice ICT integration (Hixon \& Buckenmeyer, 2009). Finally, teachers refine and increase their use of ICT in the classroom until they reach full integration (Hixon \& Buckenmeyer, 2009).

Cuban, et. al. (2001) noted that pedagogical changes as a result of continuous ICT integration were incremental over time. Teachers with high skill levels tend to achieve greater incremental change toward advanced ICT integration over time (Tuck, 2004). For teachers to move past the first stage, they must have adequate access, support, and training (Hixon \& Buckenmeyer, 2009; Mueller, et. al., 2008). It is also important to note that constructivist beliefs are required in order for teachers to reach the higher stages 
of progression toward complete ICT integration (Hixon \& Buckenmeyer, 2009). Hixon and Buckenmeyer and Mueller, et. al. also stress the importance of professional development opportunities in all stages of ICT use and integration.

Cuban, et. al. (2001) question the idea that a slow revolution toward increased ICT integration with increasing numbers of teachers embracing ICT integration will occur on its own. Some researchers suggest that full integration could require several years to achieve and the ever-changing nature of technology may increase that time (Mueller, et. al., 2008). Major findings from the National Education Association survey concluded that educators are more familiar with the use of technology, but the training they have received was inadequate to promote best-practice instruction (Tuck, 2004). This survey also identified that teacher attitudes, especially their perceived impact of ICT on their job performance, can change significantly over time based on experiences with technology (Tuck, 2004).

Ertmer and Ottenbreit-Leftwich (2010) suggest that early professional development opportunities should include basic ICT skills and then progress toward more constructivist ICT integration. Yaghi and Ghaith (2002) explain that general ICT use for things other than teaching will help teachers to build confidence for future use. Research also suggests that progression is contingent upon successful experiences, whether personal or vicarious, with ICT integration at each level (Ertmer \& Ottenbreit-Leftwich, 2010). In order to be empowered to integrate ICT into their classrooms teachers must develop specific attitudes, skills, confidence, and intentional classroom practices (Chen \& Chang, 2006). 
Cuban, et. al. (2001) identify that traditional attempts at reform have failed because they did not take into account the teachers' developmental characteristics or allocate adequate funding for professional development programs. They suggest that teachers will only be empowered by convenient, on-site professional development that is specifically geared toward the teachers involved in the program (Cuban, et. al., 2001). ICT integration requires collaboration with other classroom teachers and adequate time to develop the necessary skills and experience the necessary successes (Cuban, et. al., 2001). The obstacle most frequently identified by teachers is a lack of time for learning, development, and preparation (Cuban, et. al., 2001).

Klieger, et. al. (2010) suggest that teachers will become more invested in change if they participate in adequate professional development programs. Valanides and Angeli (2008) explain that adequate professional development is a key component in any school improvement plan and is needed to help teachers develop basic computer skills, pedagogical understandings, deeper understandings of content, and ICT enhanced inquiry teaching methods and suggest that these programs must be "carefully planned and implemented." Culp, et. al. (2005) suggest that teachers will only be able to develop the necessary skills and techniques for best-practice ICT integration through adequate professional development. The research of Kurt (2010) supports the assertion that it is imperative to develop effective training programs for teachers. As a part of that professional development, teachers must be given time and opportunities to practice the skills that they learn (Gülbahar, 2008).

In addition to adequate professional development programs, administrative and collegial support is essential to empowering classroom teachers to integrate ICT (Wright, 
1996). According to Groff and Mouza (2008), administrator support or lack thereof can be the clinch-pin of success or failure with regard to increasing ICT integration levels. Scoolis (1999) offers several suggestions for administrators and teacher-leaders attempting to encourage ICT integration in their schools. First, leadership must remember that it is asking teachers to change well-established teaching methods for something that in their mind is unproven, unpredictable, and unreliable (Scoolis, 1999). A failure to recognize the emotional issues and time constraints involved in making these changes could result in strained relationships, poor attitudes or confidence, and program failure (Scoolis, 1999). In addition to being aware the significance of change, Scoolis offers the following suggestions for administrators and leaders:

- develop a shared vision for success

- practice your own techniques in ways that are visible to your colleagues and teachers

- allow staff members to participate in the decisionmaking process

- prioritize needs

- give teachers a reason to utilize technology

- develop activities that focus on learning

- provide opportunities for the free exchange of ideas

- develop on-site training

- stay focused on a few key steps at a time

- be patient

- ensure access to necessary technologies 
- provide technical support

- maintain a sense of humor

Administrators and teacher-leaders should also remember that teachers are daily working in high stress environments with stress factors including: students who lack motivation and discipline, time constraints, extensive work loads, ever-changing environments, interactions with colleagues and administrators, parents, and technology (Al-Fudail \& Meller, 2008). Technology can add additional stress factors when teachers are forced to use technological skills above those they possess and adequate support is not provided (Al-Fudail \& Meller, 2008). This lack of fit is only one reported problem with "technostress"; participants also reported that time constraints, ICT reliability, lack of support, lack of student skills, and lack of training increased stress involved in ICT integration (Al-Fudail \& Meller, 2008).

The research of Hermans, et. al. (2008) presents the importance of developing support groups among teachers when initiating ICT integration initiatives. They found that belonging to the support groups of colleagues enabled teachers to build confidence, share success stories, understand school culture, and develop a professional community (Hermans, et. al., 2008). Prensky (2008) suggests that teachers will require three things to embrace best-practice ICT integration: examples, colleagues and administrators who support them, and successful experiences. He suggests that teacher support groups will provide advice, empathy, examples, and shared successes (Prensky, 2008).

The majority of variables predictive of ICT integration in classrooms are related to teacher computer experience, and hands-on, in-classroom, in-context practice is likely the best way for teachers to build confidence and add ICT integration to their teaching 
repertoire (Mueller, et. al., 2008). Administrators should identify and train mentor teachers before integrating widespread change (Mueller, et. al., 2008). Additionally, using the Integrating Innovations program developed by Groff and Mouza (2008) could provide teachers with a way to examine the predicted viability of ICT innovations in their classroom, at their school, with their resources.

\section{Professional Development}

Research suggests that investments for ICT in schools should be shifted to investing in the teachers who will utilize the technology (Keengwe, 2007; Culp, et. al., 2005; Pasco \& Adcock, 2007). Teacher training programs have begun to include courses on both ICT integration and constructivist teaching practices, but many teachers still require additional opportunities for educational experiences in order to adequately integrate ICT into constructivist learning environments (Wentworth \& Earle, 2003; Bebell, et. al., 2004; Pasco \& Adcock, 2007). Teachers need the support of meaningful, practical professional development programs that educate teachers about ICT integration for instructional purposes, rather than focusing on technology skills (Gimbert \& Cristol, 2004). Russell, et. al. (2003) explain that teachers need to understand the value of technology and how to integrate that technology into their instructional activities. Mainka (2007) suggests that schools must begin to view teachers as assets to be developed by investing in professional development, incorporating prior knowledge, linking training to content, ensuring ownership of learning, encouraging collaboration, building confidence, supporting ongoing staff development, and making technology an integral part of daily school life. 
Fletcher (2006) identifies that the majority of elementary teachers are not modeling or integrating ICT into their classroom activities and put forth lack of training as a major barrier to ICT integration. Fletcher suggests that professional development and required documentation could increase ICT integration in elementary classrooms. Shepherd and Mullane (2010) state that teachers are failing to integrate technology into their classrooms in meaningful and appropriate ways, but stress that the ability to select and use appropriate technology for classroom activities is an essential skill for $21^{\text {st }}$ century teachers. The results of Chen and Chang (2006) suggest that teachers are not prepared to integrate technology into the classroom in meaningful ways and cite professional development as the best means of equipping teachers for effective ICT integration. Culp, et. al. (2005) also recommend in their evaluation of historical ICT policy that investments in professional development for teachers are essential for improved ICT integration.

Professional development programs aimed at equipping teachers for effective ICT integration in a constructivist learning environment must go beyond the coverage of traditional professional development programs and help the teacher to create connections among the professional development program, their own learning, student learning, and classroom activities (Polly \& Hannafin, 2010). Not all ICT use in the classroom is the same, and not all professional development is the same. Rather teachers must be taught to focus on how the professional development activities are carried out and how ICT components are used in their classrooms (Becker, 2006). Tondeur, et. al. (2008) caution that it is important to consider cultural school characteristics when evaluating appropriate levels of ICT integration. 
According to Klieger, et. al. (2010), professional development is a key component in equipping, empowering, and encouraging teachers to implement change. Valanides and Angeli (2008) identify a lack of professional development as the greatest barrier to ICT integration. Blagojevic (2003) also explains that continuous professional development is necessary for teachers to feel comfortable using and experimenting with ICT for instructional purposes. According to Buckenmeyer (2010) reluctant teachers and administrators can be encouraged to move toward effective ICT integration through ongoing, content-specific professional development. Kagan (1992) explains that teacher knowledge and belief exists in the juncture of three areas: specific group of students, academic material to be taught, and the teacher's unique belief system.

Research has also demonstrated that teachers are not always able to identify how ICT integration can enhance their teaching and that specific, relevant, and easilyapplicable training is necessary to develop this understanding (Mueller, et. al., 2008; Culp, et. al., 2005). Hixon and Buckenmeyer (2009) suggest that effective professional development can build teacher confidence and promote more innovative approaches to technology. Their research also suggests that teachers at different stages in the progression toward ICT integration will require different types of professional development with differing levels of support (Hixon and Buckenmeyer, 2009). Teachers in the early stages may require directives from administrators (Hixon and Buckenmeyer, 2009). Teachers at the middle levels will benefit from co-teaching and hands-on training (Hixon and Buckenmeyer, 2009). Teachers at the higher levels may require reflective practice, research, and discussions with peers to promote optimal professional growth (Hixon and Buckenmeyer, 2009). Teachers at all levels require content-specific, hands- 
on, need-based technology training (Hixon and Buckenmeyer, 2009). Keengwe and Anyanwu (2007) identify that teachers need to be prepared to move from personal computer use to educational and instructional ICT use.

Groff and Mouza (2008) draw attention to the extreme pressure placed on teachers to integrate ICT into their classrooms and caution that it is imperative for these teachers to understand why they are using the technology and discern the when, where, and how of integrating ICT into their classrooms. Their research suggests that proper training is essential to equipping teachers to make these decisions in the face of pressure to use technology more and more (Groff \& Mouza, 2008). It is essential to prioritize the learning goals over the goal of ICT integration (Groff \& Mouza, 2008). Hixon and Buckenmeyer (2009) also stress the importance of equipping teachers to integrate ICT in ways that promote higher-order thinking skills. Keengwe and Anyanwu (2007) explain that teachers must understand how to use technology in ways that enhance, rather than hinder, student learning.

Teaching with technology requires a specialized set of skills surrounding pedagogical practices, technology skills, evaluation techniques, applications and connections to content, classroom management skills, and the ability to select the right tool to complete the desired learning outcomes (Ertmer \& Ottenbreit-Leftwich, 2010; Keengwe \& Anyanwu, 2007). Teachers need to have a high sense of self-efficacy, recognize technology as a valuable educational tool, and be prepared to make informed decisions about the use of technology in the classroom (Ertmer \& Ottenbreit-Leftwich, 2010). Ertmer and Ottenbreit-Leftwich suggest that teachers lack the knowledge, beliefs, and confidence to effectively integrate technology into the classroom, yet it is precisely 
this convergence of knowledge, beliefs, and confidence that will lead to equipping, empowering, and encouraging teachers toward effective ICT integration. Butzin (2000) explains that teacher preparation for Project CHILD includes a year of intensive training in effective ICT integration. Neo and Neo (2004) support the need for preparing teachers to meld ICT with content to effectively enhance student learning.

The knowledge, beliefs, and confidence of teachers regarding ICT integration in the classroom are significant determinates of how much students learn from activities involving ICT in the classroom (Chen \& Chang, 2006). Teachers require the skills to effectively evaluate software, the ability to select appropriate tools to gain optimal learning outcomes, and attitudes that promote effective ICT integration (Chen \& Chang, 2006). Teacher proficiency is strongly connected to both student success and effectiveness of in-service training (Chen \& Chang, 2006; Shepherd \& Mullane, 2010). Chen and Chang also establish that teaching methods are a significant determinate for ICT integration, teachers are more likely to experiment with new innovations following successful experience with ICT use, and the building of teacher confidence is essential in developing proficiency.

While the importance of professional development has been established, in what form should professional development programs be presented in order to achieve optimal change? Birman, Desimone, Porter, and Garet (2000) explain that most professional development programs do not meet the needs or challenges of their attendees. Viadero (2005) supports this conclusion, identifying that most professional development is too generic and fragmented to promote significant change, and many teachers view professional development as a waste of time because it is not specific to their needs. 
Viadero suggests that professional development programs need to last longer and focus on specific academic content. Klieger, et. al. (2010) suggest that a combination of traditional and reformed types of professional development can be effective with regard to ICT integration.

Birman, et. al. (2000) suggest that professional development can be designed and evaluated using three structural features: form, duration, and participation; and three core features: content focus, active learning, and coherence; but there are relationships and crossover between features. With regard to structure, they found that traditional formats tend to be shorter and lack hands-on practical opportunities, while reform formats tend to be longer and further develop the core features (Birman, et. al., 2000). They did stress however that if duration and core feature focus is strengthened, traditional workshop and conference type programs can still be effective (Birman, et. al., 2000). Core features are extremely important in determining the successfulness of any professional development program with teachers reporting that content-specific professional development that includes practical opportunities for implementation, in alignment with school culture and previous professional experiences is the most effective form (Birman, et. al., 2000).

Lee (2004-2005) presents a comprehensive professional development model that can be applied to a variety of topics, skills, and practices. The stated goals for this needsbased program are maximizing outcomes and sustaining practices (Lee, 2004-2005). This program is self-described as a combination of traditional and reform methods of professional development and incorporates a variety of instructional techniques including activities that are interactive, collaborative, involve problem-solving, content-specific, context-specific, and practical (Lee, 2004-2004). Lee explains that it is critical for any 
professional development program to be directly related to the needs of the teachers participating. Teachers who have participated in professional development for ICT integration acknowledge the usefulness of resources that are applicable to their subject of study (Lin, 2008).

A variety of strategies, as listed above, and a variety of organizational structures (i.e. seminars, conferences, workshops, study groups, mentoring, and coaching) are suggested alongside extended duration and adequate time allotment for activity completion (Lee, 2004-2005). Lack of time is often identified as a factor in failure to create lasting change from professional development information (Lin, 2008). Lee also identifies that programs designed and implemented with teachers from the same school, especially when provided at their school, are better able to facilitate discussions, problem-solving, and enthusiasm. The first step in developing a professional development program is to identify the needs of the teachers involved (Lee, 2004-2005). Additionally, teachers should be included in the decision-making process, project goals should correspond to teacher needs, collaborative groups of similar content and context should be formed, and a connection between learning and practice must be established (Lee, 2004-2005).

Glazer, et. al. (2005) explain the use of a professional development program known as Collaborative Apprenticeship to encourage ICT integration. Collaborative Apprenticeship exchanges ineffective, generic seminars for a form of professional development that is continuous, on-site, and uses experienced teachers as mentors for their colleagues (Glazer, et. al., 2005). This format allows for the experience to take place in authentic environments that offer practical opportunities for practice and 
immediate feedback on success (Glazer, et. al., 2005). Glazer, et. al. stress that professional development programs need to be well-planned, well-organized, allow opportunities to reflect and recognize success, and provide teachers with adequate support. As teachers progress through the levels of ICT integration, the necessary support lessens (Glazer, et. al., 2005). In order for Collaborative Apprenticeship to be implemented, shared time and teacher commitment are necessary factors (Glazer, et. al., 2005).

Teacher beliefs are also an important factor to consider given the nature of technology and the hopes of ICT proponents that ICT integration will lead to constructivist teaching methods (Hixon and Buckenmeyer, 2009). Kagan (1992) explains that teacher beliefs are intensely private and are rarely altered through reading and listening to research. Rather, true belief alterations require practical opportunities and experienced successes (Kagan, 1992). According to Kagan, professional development aimed at altering ingrained teacher beliefs must include several steps including: explicitly stating beliefs, challenging the adequacy of beliefs, giving extended opportunities for examining beliefs, and providing opportunities to integrate new knowledge into their belief systems.

With regard to technology specifically, Waddoups, Wentworth, and Earle (2004) identify the need for examples and experiences with lessons involving ICT integration. However, many current professional development programs do not provide these necessary opportunities and fail to move past lower-level uses of ICT in the classroom (Hixon and Buckenmeyer, 2009). Also lacking are programs that are need-based and offered at the appropriate step in progression for the teachers involved (Hixon and 
Buckenmeyer, 2009; Levin \& Wadmany, 2008). The work of Peck, et. al. (2002) suggests that training students to aid in tech support can stretch limited resources while providing necessary support to teachers and opportunities for growth for students.

Glazer, Hannafin, Polly, and Rich (2009) explored the factors and interactions that influenced ICT integration through professional development. The premise is that the failure of efforts involving ICT integration result from a lack of training in ICT integration for instructional purposes (Glazer, et. al., 2009). Research demonstrates that professional development for ICT integration should take place in the everyday environments of the teachers who will be integrating the technology (Glazer, et. al., 2009). The collaboration of teachers is essential to developing and maintaining a community of practice that serves as a support network during integration attempts (Glazer, et. al., 2009). Teacher-leaders with prior training are also a necessary component to providing on-time support for novice innovators (Glazer, et. al., 2009). Research demonstrates that these peer teachers develop relationships that are sustained outside of allocated professional development time and provide various forms of support to each other including advice, conflict resolution, comfort, brainstorming, motivating, reinforcing, and modeling (Glazer, et. al., 2009).

According to Steketee (2005), professional development approaches to ICT integration fall into one of four categories: skills development, pedagogical approach, subject-specific approach, and practice-driven approach. When considering the progressive nature of ICT skill acquisition, the first approach is appropriate for teachers who lack basic ICT skills because they cannot move forward until they develop the adequate skills to do so (Steketee, 2005). For teachers who have basic ICT skills, it is 
necessary to provide adequate pedagogical training and belief system evaluation with the goal of eventually moving toward subject-specific, practical professional development opportunities (Steketee, 2005). True change and effective ICT integration is only achieved in the higher levels of development (Steketee, 2005; Gimbert \& Cristol, 2004). Wright and Lesisko (2008) also identify the importance of professional development being on-going and need-based in order to promote effectual change.

With regard to collaboration, Pascopella (2008) suggests the following guidelines: high administrative expectations, inclusive acceptable use policy, team-building opportunities, utilization of teacher-leaders, and streamlined site filtering. To review the work of Scoolis (1999), staff development in ICT integration should include: recognizing change as a process, identifying and focusing on what is needed most, giving teachers a reason to use the technology, supporting existing activities, exchanging ideas, developing training on-site, remaining focused, being patient, ensuring access, and providing technical support. Chen and Chang (2006) remind of the necessity to ensure adequate support during and after the professional development program, provide on-going training, and match training to teacher needs. Demonstrations, assisting with setup, and brainstorming are just a few of the ways that support for integration can be offered (Chen \& Chang, 2006). Additionally, some level of in-class support will likely be needed until training has progressed far enough to ensure continuing change and integration (Chen $\&$ Chang, 2006; Mueller, et. al., 2008).

Keengwe, et. al. (2008a) identify some responsibilities that teacher participants have in professional development for ICT integration. Teachers must strive to accomplish activities at their highest level (Keengwe, et. al., 2008a). Teachers should 
create relationships between active learning and active teaching (Keengwe, et. al., 2008a). Appreciation for the potential of technology and the power of effective integration are essential for fueling the desire to accomplish integration tasks (Keengwe, et. al., 2008a). Teachers should desire to develop leadership skills in order to become role models for effective integration in their schools (Keengwe, et. al., 2008a). Working to learn the benefits of technology and incorporate ICT into classroom activities in ways that increase student motivation and learning are also essential teacher responsibilities (Keengwe, et. al., 2008a). The most effective way to ensure teacher growth and change with regard to ICT integration is to provide very specific ideas and resources for contentrelevant integration, support teachers in risk-taking and innovative use of ICT in the classroom, and provide teachers the opportunities to experience personal successes with ICT integration in their classrooms (Ertmer \& Ottenbreit-Leftwich, 2010; Mueller, et. al., 2008; Levin \& Wadmany, 2008).

Remember that the ultimate goal of professional development is actually to increase or improve student learning (Polly \& Hannafin, 2010). Professional development aimed at this goal should focus on the content to be learned and evaluating student learning, encourage teacher-ownership, help develop teacher knowledge of content and pedagogy, establish opportunities for collaboration, remain ongoing in a convenient location, and encourage teacher reflection and evaluation (Polly \& Hannafin, 2010). Some research also suggests that adequate professional development for ICT integration will also include practical advice for classroom management during the use of computers and other ICT components (Erdoğan, Kursun, Tan Sisman, Saltan, Gök, \& Yildiz, 2010). 


\section{Summary}

Government policy and investments in ICT components promote ICT integration in today's schools. It has been suggested that in order to adequately motivate and prepare today's students for the twenty-first century, technology must be an essential component in their education. Investigations of the historical use of ICT in classrooms illuminate the limited state of ICT integration across the country. Investments in ICT components have been spawned by the vast promises of ICT integration including creativity, innovativeness, collaborative learning, intervention, and inquiry-learning. However, most would agree that these promises are only fully realized alongside constructivist pedagogy.

Constructivist pedagogy differs from traditional pedagogy in that it promotes student-centered, inquiry learning. Benefits of constructivist pedagogy include the tendency to promote higher-order thinking skills and collaborative learning. It is believed that technology can be utilized to fuel and enhance constructivist learning. Current ICT use falls short of fulfilling the promises of researchers, reformers, and proponents of ICT integration. Additionally, the challenges of integrating ICT into classrooms present seemingly insurmountable barriers for classroom teachers.

ICT integration is a complex phenomenon involving a significant number of interacting school, technological, administrative, student, and teacher factors. Teachers have often taken the blame for the lack of ICT integration due to their integral role in effective integration. Teachers ultimately have the final say in what activities occur in the classroom and their beliefs, attitudes, self-efficacy, innovativeness, and skill levels are just a few of the factors that influence their decisions. Additionally, these factors 
interact with the school, technological, administrative, and student factors for a nearly endless set of possible circumstances as unique as each individual teacher. Teachers must be equipped, empowered, and encouraged to include ICT in their instructional repertoire.

In order to reach this goal, adequate professional development programs must be established on-site, allowing for convenience, practicality, and extended duration. While professional development will only address the teacher factors involved in integration, it is an essential step toward ICT integration. Professional development should meet the individual needs of teachers involved in the program and aid them in their progression through the stages of ICT integration. Adequate professional development must be needbased, continuous, on-site, and content-specific. It should offer practical, hands-on experience and be supplemented by adequate support from colleagues, administrators, and technical staff. 


\section{PROFESSIONAL DEVELOPMENT PROGRAM}

\section{Phase One}

Objectives:

- The implementer will identify the strengths and weaknesses of the current school culture toward large-scale ICT integration.

- The implementer will identify and recruit optimal teacher-mentor candidates.

- The implementer will work alongside administration and teacher-mentors to develop a school vision for ICT integration.

This phase will be carried out through a series of meetings with appropriate stakeholders.

Procedures:

- Complete a school-wide survey of all teachers (Appendix I).

- Carry out interviews with select teachers who have been identified as possible candidates for teacher-mentors.

- Develop school-wide vision and support for ICT integration through a series of meetings with administration, teacher-mentors, and other stakeholders.

- Present the vision and plan to the greater school community (i.e. teachers, staff, parents, students, donors, and other stakeholders).

\section{Phase Two}

Objectives:

- The implementer will train teacher-mentors in more advanced computer skills, constructivist ICT integration, and mentorship responsibilities. 
- The implementer will establish streamlined network and Internet access for teacher-mentors.

- Teacher-mentors will explicitly define their core beliefs.

- Teacher-mentors will design lessons that employ constructivist teaching methods alongside ICT integration.

- Teacher-mentors will explore the advanced features of common production software.

- Teacher-mentors will establish a support network among themselves.

- Teacher-mentors will create a bank of lesson resources.

- Teacher-mentors will build classroom websites to facilitate ICT integration in their classrooms.

This phase will be carried out in two parts: a seven to ten day intensive summer seminar followed by monthly meetings of four to six hours throughout the school year.

Procedures:

- Prior to the start of the intensive summer seminar, the implementer should limit Internet/website blockers and filters on teacher-mentor computers and/or provide access codes to all teacher-mentors.

\section{Day One}

- What makes a leader/mentor?

* Teacher-mentors participate in a brainstorming discussion of characteristics found in a quality mentor or leader.

* Teacher-mentors will work in pairs to use an online concordance/word study to create a biblical picture of leadership/mentorship. 
Teacher-mentors discuss their findings as a group.

* The implementer uses a prepared sample to give a 10-15 minute minilesson on the basic features of the software program Inspiration.

* Teacher-mentors use the program to create a visual representation of the key question and practical applications of character/leadership traits.

- Survey: Belief Meets Action (Appendix II)

* Teacher-mentors complete a survey to help identify their core beliefs and the beliefs their actions show.

* Teacher-mentors generate lists of teaching and learning activities they would identify as components of constructivist or traditional teaching. The implementer should guide a discussion if any activities need to be moved to a different category and add any missed components to the appropriate category.

* The implementer should guide teacher-mentors as they go over their surveys in small groups and discuss any discrepancies that are identified.

- Microsoft Word Project

Teacher-mentors select a topic from their subject area and create a review sheet, test, or sample student project that involves the use of tables, textboxes, and graphics.

\section{Day Two}

- Lesson Comparison

* One-half of the teacher-mentors work to create a traditional lesson on a topic from their field of study. 
One-half of the teacher-mentors work to create a constructivist lesson from their field of study.

* Each group of teacher-mentors teaches their lesson to the remaining half of teacher-mentors.

* Teacher-mentors compare and contrast the perceived benefits and challenges of each teaching type.

- Microsoft Publisher Project

Teacher-mentors make a poster that could be used during a unit of instruction that they will teach during the next school year.

Teacher-mentors take a field trip to a local copy center where they have their posters printed and explore the other printing, binding, and presentation options that the center offers.

\section{Day Three}

- Constructivism meets ICT

* Teacher-mentors review the basic tenants of constructivism and ICT integration.

- Unit Creation

* Teacher-mentors individually prepare to teach a unit during the first month of school using primarily constructivist teaching strategies. One requirement is that ICT components be used for at least 50 percent of the unit activities.

* Teacher-mentors participate in a progress discussion halfway through the day's time and at the end of the day's time. 
The implementer should provide support as needed throughout the unit planning and preparation.

$\underline{\text { Day Four }}$

- Non-linear Microsoft PowerPoint Project

* The implementer presents a sample non-linear PowerPoint and quickly reviews the necessary features of Microsoft PowerPoint.

* Teacher-mentors develop one non-linear kiosk PowerPoint activity for learning a new concept.

* Teacher-mentors develop one non-linear kiosk PowerPoint activity to be used for review purposes.

- Microsoft PowerPoint Review

* Teacher-mentors trade PowerPoint activities. They explore their partner's activity and complete a review of the activity.

* Teacher-mentors discuss strengths and weaknesses identified in the activities, planning for the activities, and preparation of the activities.

- Unit Creation

* Teacher-mentors discuss their progress on the creation of their unit plans.

* Teacher-mentors work together to resolve any problems their colleagues are encountering in creating their plan or materials. 


\section{Day Five}

- Building a Resource Bank

The implementer briefly shares Internet search strategies with the teachermentors and invites their input into search strategies they have found effective.

* The implementer shares some sample resources (i.e. you-tube downloader, InfoOhio, ITunes, Intel AppUp, etc.) with the teacher-mentors.

- Treasure Hunt for Resources

* Teacher-mentors embark on a treasure hunt for electronic resources.

* Teacher-mentors participate in a progress discussion halfway through the day's time and at the end of the day's time. Teacher-mentors are encouraged to work together and share findings throughout the time they are searching for resources as well.

* The implementer should provide support as needed throughout the resource treasure hunt.

- Electronic Resource Treasury

* Teacher-mentors organize a searchable resource treasury online and/or on their computers. Items categorized on individual computers should be backed up to a flash drive and CD as well.

- Software Suggestions

Teacher-mentors and the implementer work together to prepare a list of software suggestions. 
The implementer presents the software suggestions to administration for budgetary consideration.

\section{$\underline{\text { Day Six }}$}

- Windows Movie Maker Project

* Special Note: Another video application (i.e. IMovie) could also be used.

* The implementer goes over features and basic use of the video application selected.

Teacher-mentors discuss possible classroom uses and applications.

* Teacher-mentors develop a video for classroom use. View some of the videos as time allows.

* Teacher-mentors discuss the feasibility of aiding students in the creation of their own videos to demonstrate learning. The implementer shares a sample video submitted by a student for a fifth grade history project.

\section{$\underline{\text { Day Sevent }}$}

- Classroom Web Site Creation

* Teacher-mentors will create a classroom website. Currently, three options seem most viable for this task.

Option 1: Teachers can utilize the online site weebly.com free of charge to use templates and design a viable website for their classroom.

Option 2: Teachers can utilize Microsoft Word or another software program (i.e. Dreamweaver) to create a custom web page. That web page can then be hosted on 
ipage.com or bluehost.com and the teacher will be reimbursed for the monthly expense through the school.

Option 3: Teachers can utilize Microsoft Word or another software program (i.e. Dreamweaver) to create a custom web page. That web page can then be hosted as a part of our school website.

- Business Card Project and Printing

Teacher-mentors use Microsoft Publisher to design and print personal business cards.

\section{Monthly Meetings}

- The implementer should be prepared to provide technical and networking support for setup and implementation of units involving extensive ICT integration throughout the first month of the school year.

Initial Meeting

- Teacher-mentors discuss and review their unit implementation including: strengths and weaknesses perceived, difficulties encountered, and successes experienced.

- Teacher-mentors identify a lesson or unit to use ICT integration with during the next month. Teacher-mentors should video tape one lesson and bring it with them to the next meeting. 


\section{Subsequent Meetings}

- Lesson Review and Discussion

Teacher-mentors view each others' videos and identify constructivist and traditional teaching elements in each lesson.

* Teacher-mentors discuss strengths and weaknesses of lessons viewed.

- Struggles and Solutions

* Teacher-mentors identify struggles encountered in unit implementation and brainstorm solutions together.

- Ideas and Resources

* Teacher-mentors share new ideas or resources they have discovered and add to their resource treasuries.

- Preparation for Next Meeting

* Teacher-mentors identify lessons or units to attempt ICT integration in for the next month. Teacher-mentors should video tape one lesson and bring it with them to the next meeting.

Last Meeting of the Year

- Teacher-mentors identify and discuss the successes they have experienced throughout the school year with ICT integration.

- Teacher-mentors discuss and evaluate the experience as a whole.

- Teacher-mentors review the role of a mentor/leader.

- The implementer should remain available for support as needed throughout the program. 


\section{Phase Three}

Objectives:

- Non-use and limited-use teachers will develop basic computer skills and be encouraged to practice these skills for practical purposes.

This phase will be implemented through bi-monthly meetings during the school year. Phase three can be implemented before phase two has been completed. Teachers who fall into the categories of non-use and limited-use may require administrative directives to encourage initial participation.

Procedures:

- The implementer must be certain that adequate support from technical staff, administration, and teacher-mentors is conveniently available as activities are implemented in order to allow these teachers to experience success when utilizing technology.

- Basic E-mail Skills

* The implementer provides training in basic e-mail skills using the First Class program utilized by the school district.

* The implementer requires daily e-mail contact between themselves and the teacher participants for the next two weeks.

* The implementer requires twice weekly contact for the two weeks following the previous step.

- School-wide Grading and Communication Program

* The implementer provides training and set-up assistance for the Cornerstone grading and communication program utilized by the school. 
Teachers use Cornerstone for tracking attendance and grades.

* Teachers use Cornerstone for accessing communication information for students, parents, and colleagues.

* The implementer provides continued support on an as needed basis throughout the school year.

- Microsoft Word

* The implementer provides basic training and support throughout the project.

* Teachers use the basic features of Microsoft Word to make and submit lesson plans for the next four weeks.

- Linear Microsoft PowerPoint

The implementer provides basic training and support throughout the project.

* Teachers use the basic features of Microsoft PowerPoint, including clip art, pictures, text boxes, templates, and design, to create a devotional slide show over the next two weeks and share their slide show on their next date to lead faculty devotional time.

- Basic Internet Searching

- The implementer shares basic search strategies when using standard Internet search engines.

* Teachers create a list of websites in their favorites that could be used as resources for them professionally or as resources for their students. 


\section{Phase Four}

Objectives:

- Teachers with personal and professional ICT proficiency will begin to utilize ICT in the classroom for instructional purposes.

- Teachers who participate in this phase will be prepared to complete phase one of this program upon their satisfactory completion of phase four.

This phase will be carried out in two parts: a three to four day intensive summer seminar followed by monthly meetings of four to six hours throughout the school year. This phase may be implemented over several stages as necessary and may be done as a requirement or on a voluntary basis.

Procedures:

- Prior to the start of the intensive summer seminar, the implementer should limit Internet/website blockers and filters on teacher computers and/or provide access codes to all teachers participating in the program.

\section{Day One}

- The implementer should arrange for trained teacher-mentors to interact with teachers and participate in this activity alongside participants.

- $\quad$ Building a Resource Bank

* The implementer briefly shares Internet search strategies with the teachers and invites their input into search strategies they have found effective.

* The implementer shares some sample resources (i.e. you-tube downloader, InfoOhio, ITunes, Intel AppUp, etc.) with the teachers. 
- Treasure Hunt for Resources

* Teachers embark on a treasure hunt for electronic resources.

The implementer and teacher-mentors should provide support as needed throughout the resource treasure hunt.

- Teacher-mentors share some of their positive experiences with technology in the classroom and learning to effectively integrate ICT into their classroom.

- The implementer facilitates a question and answer time between teacher participants and teacher-mentors.

\section{Days Two and Three}

- Teachers identify a unit or short series of lessons they would like to attempt ICT integration with during the first two months of school.

Suggestions for Unit Selection:

Teachers select a subject and topic they are confident and comfortable teaching.

$>$ Teachers select technology programs they are confident with and their students possess the skills to implement.

- Teachers complete the I inventory for their planned unit. Teachers discuss and adjust their unit based on their findings from the I5 inventory.

- The implementer matches up teacher-mentors with teacher participants.

- Teachers develop and prepare for a unit plan with guidance and support from the implementer and teacher-mentors. 


\section{$\underline{\text { Day Four }}$}

- Teachers discuss the pros and cons of their experience planning a unit that contains ICT integration.

- The implementer facilitates an open-forum discussion of planned units.

- The implementer facilitates a discussion of anticipated struggles with implementation and possible solutions to these struggles.

\section{Monthly Meetings}

- The implementer and teacher-mentors should be prepared to provide technical and networking support for setup and implementation of units involving ICT integration throughout the first two months of the school year.

\section{Initial Meeting}

- Teachers discuss and review their unit implementation including: strengths and weaknesses perceived, difficulties encountered, and successes experienced.

- Teachers identify a lesson or unit to use ICT integration with during the next month. Teachers should video tape one lesson and bring it with them to the next meeting.

Subsequent Meetings

- Lesson Review and Discussion

* Teachers view each others' videos and discuss strengths and weaknesses of lessons viewed.

- Struggles and Solutions

Teachers identify struggles encountered in unit implementation and brainstorm solutions together. 
- Ideas and Resources

* Teachers share new ideas or resources they have discovered and add to their resource treasuries.

- Preparation for Next Meeting

Teachers identify lessons or units to attempt ICT integration in for the next month. Teachers should video tape one lesson and bring it with them to the next meeting.

Last Meeting of the Year

- Teachers identify and discuss the successes they have experienced throughout the school year with ICT integration.

- Teachers discuss and evaluate the experience as a whole.

- Teachers are interviewed for possible participation in the teacher-mentor training phase.

- The implementer should remain available for support as needed throughout the program.

\section{Phase Five}

Objectives:

- Phase five of this program facilitates ongoing and continuous training and growth in effective ICT integration.

Procedures:

- Re-implement each phase of the professional development program as time, interest, and need arise. 


\section{DISCUSSION}

The need for adequate professional development for effective ICT integration is well-established and extensively outlined in chapter two of this thesis, but the individual decisions made in the creation of this professional development program may be less obvious. The program begins with a survey of teachers in order to ascertain the current school culture with regard to ICT integration. This survey is followed by meetings with administration and teacher-leaders to establish a school vision for ICT integration. The purpose of this survey is to make teachers, administrators, and other stake-holders aware of the prevailing school culture. If this is ignored, the implementer may be setting the program up for failure. According to Chaptal (2002), an existing school culture that does not promote ICT integration can significantly hinder attempts by individual teachers to integrate ICT into their classrooms. Hixon and Buckenmeyer (2009) identify school culture as a first-order barrier to integration.

The purpose of including administrators and teachers in the development of a school-wide vision for ICT integration is two-fold. First, it is important to include teachers in the decision-making process (Tuck, 2004). Secondly, it ensures that the administration will be behind efforts to increase ICT integration. According to Keengwe, et. al. (2008a), administrative support plays an essential role in ICT integration. Tondeur, et. al. (2009) also identifies the importance of effective leadership to perpetuating effective ICT integration. From my own observations, I hypothesize that the current school culture would support ICT integration, but would hesitate to embrace it in its most effective form- alongside constructivist pedagogy. The school currently relies heavily 
upon the purchased textbooks and workbooks for instruction, with the promotion of reading as many text pages and completing as many workbook pages as possible. It is my belief that this stems from an era when the school was growing and many of the teachers were not specifically trained in education and more traditional teaching methods were the norm.

Despite this fact, the administration and school board have demonstrated a strong desire to see the school grow in more dynamic forms of teaching through professional development. Recently, they have demonstrated a willingness to rely more heavily upon the expertise of individual teachers than on the purchased textbooks. They also have a strong desire to see the school become technologically equipped and have developed a long term technology plan for reaching this goal. Additionally, they consciously invest in technology each year in an attempt to move toward those goals. Because of these actions, I believe that the administration and school board would be very interested in the information contained in this thesis and support the program that is based on the research completed. Although it would only be solidified after budgetary considerations, the administration would also consider budgetary investments in the program. Essentially, the purpose of the first phase of this professional development program is to evaluate and create a school culture that supports and encourages ICT integration. It is important to minimize the obstacles that teachers will encounter if the program is to be effective in empowering them to increase ICT integration in their classrooms.

The final objective of the first phase is to identify teacher-mentor candidates. It is apparent from the research that having strategically placed and trained mentor teachers can provide the necessary support for hesitant teachers to attempt ICT integration in their 
classrooms and experience success with their initial attempts at integration (Glazer, et. al., 2005). Glazer, et. al. identified this model of professional development as Collaborative Apprenticeship. Part of the survey will identify those teachers who already possess advanced computer skills and have taken at least the initial steps of experimenting with ICT integration in their classrooms. The interview will serve to identify those teachers who are willing to broaden their understanding of effective ICT integration in the classroom and serve as mentors to help support other teachers in their attempts to integrate ICT into their classrooms. Because of the significant time investment, these teachers would need to participate on a voluntary basis. Teachers could be encouraged to participate in the program through a small stipend offered by the school or the opportunity to earn CEUs for participation in the program. As an accredited school, we are able to work with ACSI to host professional development meetings that allow teachers to earn CEUs upon their approval. Ideally, both high school and elementary teachers would be represented during this phase of the program.

The objectives of the second phase of the professional development program focus on preparing the teacher-mentors. First, these teachers must be trained in how to be an effective mentor. This is to ensure that they are able to adequately support their colleagues in the next portion of the professional development program. Because this program is designed specifically for a Christian school, it is desirable that a biblical understanding of leadership be gained before these teachers serve as mentors to their colleagues. Availability and access to support is essential for the majority of teachers to experience success (Groff \& Mouza, 2008). The importance of adequate support is also 
the justification for encouraging the teacher-mentors to build a support network among themselves.

Secondly, web access and network access should be streamlined for these teachers, including the provision of access codes to bypass blockers. The teachers should be men and women of integrity and limited access often provides undue frustration when planning for lessons that involve ICT integration. For example, an interactive website on the Civil War may be blocked because it is considered a "game" or because of the words "war" or "guns" when it is actually a very suitable site for students. Streamlining access for teachers provides them with the ability to make decisions for their specific needs. As established in chapter two of this thesis project, unpredictability is one hindrance to ICT integration in the classroom.

Possibly the most important objective of phase two is the development of teachers who utilize ICT integration in its most powerful form, ICT integration alongside constructivist pedagogy (Hopson, et. al., 2001-2002; Keengwe, et. al., 2008b). Included in phase four of this professional development is the objective that teachers will be prepared to go through the phase two training once they have completed phase four- the ultimate goal being that these teachers too would be able to utilize ICT integration in their classrooms alongside constructivist pedagogy. As a part of this objective, the implementer will attempt to utilize constructivist teaching methods for a majority of the professional development program in order to establish an effective example for the teachers (Prensky, 2008). Kagan (1992) identifies the importance of helping teachers to make their internal beliefs explicit to facilitate effective evaluation of those beliefs. 
Additionally, teachers must understand and experience the benefits of constructivist pedagogy (Wentworth \& Earle, 2003; Bebell, et. al., 2004; Pasco \& Adcock, 2007).

The inclusion of training in common production software, creation of a bank of lesson resources, and creation of a classroom website are also included in this phase of the professional development program. Certainly, it is important to recognize that the specific software programs were included because of their current availability to the school this program was designed for and their general popularity in educational and other arenas, rather than because of specific research carried out on these programs. Because these teachers already possess a working knowledge of technology, the experiences contained in this professional development program will be needs-based (Lee, 2004-2005; Ertmer \& Ottenbreit-Leftwich, 2010; Wright \& Lesisko, 2008) by focusing on more advanced features of the included software. Additionally, the inclusion of this element in the program will ensure that these teachers are confident when facilitating lessons in their classrooms that include the use of these programs and providing support to the teachers they will mentor in the future (Groff \& Mouza, 2008; Mueller, et. al., 2008; Chen \& Chang, 2006; Van Braak, et. al., 2004).

The creation of a bank of lesson resources and a classroom website are for organizational purposes and to facilitate future ICT integration while simultaneously providing opportunities for the building of a support network between the teachermentors. While many of these resources in the resource treasury may be included in each teacher's website, my vision for this bank of resources is that teachers will locate not only links to websites, but also pictures, videos, and other documents that the teachers can access quickly for use in their classrooms and lesson preparations. For this reason, 
teachers will organize the resources they find in a series of subject and chapter folders. Hyperlinks to websites will be kept in a word document with a brief description, again sorted by subject and chapter. The desired links would also be included on the teacher's website for student access and use. Three options have been listed for the website creation. I believe that option number one will be the most viable for timeframe, cost, and ease of use. However, it is important to note that if teachers prefer to use either option two or three, we would have easy access to trained individuals and support teams for using a web host to publish these sites.

Finally, the decision to include a combination of an intensive summer seminar session and meetings throughout the school year is two-fold: it takes advantage of the current school schedule without overwhelming teachers and facilitates on-going training and support (Wright \& Lesisko, 2008; Chen \& Chang, 2006). The purpose of the videotaped lessons is to allow teachers to see their internal beliefs in action (Lim \& Chai, 2008; Russell, et. al., 2003). Discussions and reviews of lessons allow for continuous improvement in lessons involving ICT integration and provide support for teachers who are attempting to integrate ICT alongside constructivist pedagogy.

The purpose of phase three of this professional development program is to meet the individual needs of non-use and limited-use teachers. One of the most important characteristics of effective professional development is that it is needs-based (Lee, 20042005; Ertmer \& Ottenbreit-Leftwich, 2010; Wright \& Lesisko, 2008). These teachers need to be met where they are at and eased into ICT use rather than being thrust into attempting integration before they are ready. Hixon \& Buckenmeyer (2009) explain that teachers who are at this point may require administrative directives in order to encourage 
initial participation. The elements included in this phase are designed to help these teachers learn to complete commonly required professional tasks more efficiently without overwhelming them.

Phase four of this professional development program is designed to meet the needs of the majority of classroom teachers, as they are expected to fall based on government reports about the current use of ICT in classrooms (Tuck, 2004). These teachers have a working knowledge of computers and frequently use them for professional tasks, but for any of a variety of reasons they have not yet implemented ICT into learning activities in their classrooms (Chaptal, 2002; Peck, et. al., 2002; Kromhout \& Butzin, 1993; Cuban, 1994; Kurt, 2010). Research recognizes that teachers move through phases with regard to ICT integration (Hixon \& Buckenmeyer, 2009; Ertmer \& Ottenbreit-Leftwich, 2010), thus the focus of this phase of the program is to encourage success with ICT integration. As a result, this phase will not focus on constructivist pedagogy, though the implementer will continue to use constructivist pedagogy as an example of its effectiveness.

The activities included in phase four of this professional development program will be completed alongside the teacher-mentors to foster relationships between the teacher-mentors and their colleagues who are participating in this phase of the program. Teachers will develop lessons with support that will enable them to experience success with ICT integration. The use of the I5 inventory to aid in decision-making is included to equip teachers to make effective decisions about ICT integration in their classrooms (Groff \& Mouza, 2008). 
The remaining elements included in phase four of this professional development program correlate strongly with the elements included in phase two of this program and the reasons identified for that phase should be included here also. The inclusion of training in common production software and the creation of a bank of lesson resources are both also included in this phase of the professional development program. Again, it is important to recognize that the specific software programs were included because of their current availability to the school this program was designed for and their general popularity in educational and other arenas, rather than because of specific research carried out on these programs. The creation of a bank of lesson resources was scaled down for this portion of the program due to the needs of the individual teachers involved, but is still included to foster organization, encourage ideas, and develop relationships between teachers and teacher-mentors.

Finally, the decision to include a combination of an intensive summer seminar session and meetings throughout the school year is two-fold: it takes advantage of the current school schedule without overwhelming teachers and facilitates on-going training and support (Wright \& Lesisko, 2008; Chen \& Chang, 2006). The purpose of the videotaped lessons is to allow teachers to identify successes and struggles with ICT implementation in their classrooms (Ertmer \& Ottenbreit-Leftwich, 2010; Groff \& Mouza, 2008; Mueller, et. al., 2008; Levin \& Wadmany, 2008).

Research strongly indicates that the most effective professional development programs are on-site, on-going, and needs-based (Lee, 2004-2005; Ertmer \& OttenbreitLeftwich, 2010; Wright \& Lesisko, 2008; Chen \& Chang, 2006). This understanding of adequate professional development was the driving force behind the development of this 
program. This understanding of professional development was combined with research on constructivist pedagogy and ICT integration to create a professional development program that will equip, empower, and encourage teachers to effectively integrate ICT in their classroom in ways that enhance the learning experience for their students.

Given the yearly investments in technology at this school and the school's expressed desire to equip and inspire their students to become future leaders in their community, this professional development initiative will be a significant step forward in being good stewards of the resources the teachers have available to them. It will benefit the students of this school by equipping their teachers to create engaging, authentic lessons using best practice pedagogy. Students will learn skills necessary to participate efficiently and effectively in the Information Age. Additionally, teachers will experience a professional development program designed specifically for them. This program will give them valuable ICT skills, stimulate their innovativeness, establish collaborative discussions with colleagues, and provide ample opportunities for assessing their success in the classroom. Most importantly, it will enable them to use all of the tools available to them to provide their students with the best possible learning experiences.

Whenever attempts are made to require more time of hard-working teachers, some resistance is to be expected. It will be important to help teachers see the value of this program for their professional lives and the lives of their students. If too much resistance is encountered, it may be more effective to begin the program with a smaller number of volunteer teachers rather than a school-wide initiative. Feedback from this initial group of teachers would provide valuable insight for future implementations of this program and the development of other on-site professional development programs. 


\section{REFERENCES}

Adams, W. K., Reid, S., LeMaster, R., McKagan, S. B., Perkins, K. K., Dubson, M., et. al. (2008). A study of educational simulations part 1-engagement and learning. Journal of Interactive Learning Research, 19, 397-419.

Al-Fudail, M. \& Mellar, H. (2008). Investigating teacher stress when using technology. Computers \& Education, 51, 1103-1110.

Allen, L. (2008, April). The technology implications of 'A Nation at Risk'. Phi Delta Kappan, 608-610.

Ayas, C. (2006). An examination of the relationship between the integration of technology into social studies and constructivist pedagogies. The Turkish Online Journal of Educational Technology, 5, article 2.

Baek, Y. K. (2008). What hinders teachers in using computer and video games in the classroom? Exploring factors inhibiting the uptake of computer and video games. CyberPsychology \& Behavior, 11, 665-671.

Baker, E. A. (2007). Elementary classroom web sites. Journal of Literacy Research, 39, $1-36$.

Bebell, D., Russell, M., \& O’Dwyer, L. (2004). Measuring teachers' technology uses: Why multiple-measures are more revealing. Journal of Research on Technology in Education, 37, 45-63.

Becker, H. J., \& Ravitz, J. (2000). The influence of computer and internet use on teachers' pedagogical practices and perceptions. Journal of Research on Computing in Education, 31, 356-384. 
Becker, J. D. (2006). Digital equity in education: A multilevel examination of differences in and relationships between computer access, computer use and state-level technology policies. Education Policy Analysis Archives, 15(3), 1-38.

Birman, B. F., Desimone, L., Porter, A. C., \& Garet, M. S. (2000, May). Designing professional development that works. Educational Leadership, 28-33.

Blagojevic, B. (2003). Funding technology: Does it make cents? Young Children, 58(6), 28-33.

Boling, E. C., \& Beatty, J. (2010). Cognitive apprenticeship in computer-mediated feedback: Creating a classroom environment to increase feedback and learning. Journal of Educational Computing Research, 43, 47-65.

Buckenmeyer, J.A. (2010). Beyond computers in the classroom: Factors related to technology adoption to enhance teaching and learning. Contemporary Issues in Education Research, 3(4), 27-35.

Butzin, S. M. (2000). Project CHILD: A decade of success for young children. T.H.E. Journal, 27(11), 90-94.

Butzin, S. M. (2001). Using instructional technology in transformed learning environments: An evaluation of Project CHILD. Journal of Research on Computing in Education, 33, 367-373.

Butzin, S. M. (2002). Project CHILD: The perfect fit for multimedia elementary schools. Multimedia Schools, 9(6), 14-16.

Cady, D., \& Terrell, S. R. (2007-2008). The effect of the integration of computing technology in a science curriculum on female students' self-efficacy attitudes. Journal of Educational Technology Systems, 36, 277-286. 
Callister, T. A. Jr., \& Dunne, F. (1993). The computer as a doorstop: Technology as disempowerment. Education Digest, 58(9), 4-7.

Carnevale, D. (2004). Report says educational technology has failed to deliver on its promises. Chronicle of Higher Education, 50(43), A30.

Casey, J. M. (2008, June/July). Students ‘power down' for school: Technology left behind. Reading Today.

Casey, J. M. (2010). Students power down and dumb down for school: A commentary. The California Reader, 43(2), 19-22.

Chaptal, A. (2002). Is the investment really worth it? Education Media International, 8799.

Chen, C.-H. (2008). Why do teachers not practice what they believe regarding technology integration? Journal of Educational Research, 102, 65-75.

Chen, J.-Q. \& Chang, C. (2006). Using computers in early childhood classrooms: Teachers' attitudes, skills and practices. Journal of Early Childhood Research, 4, $169-188$.

Choi, I., Lee, S. J., \& Jung, J. W. (2008). Designing multimedia case-based instruction accommodating students' diverse learning styles. Journal of Educational Multimedia and Hypermedia, 17, 5-25.

Clements, D. H., \& Sarama, J. (2003, November). Young children and technology: What does the research say? Young Children, 34-40.

Cuban, L. (1994). Computers meet classroom: Who wins? Education Digest, 59(7), 5053. 
Cuban, L. (1999a, January). High-tech schools, low-tech teaching. The Education Digest, 53-54.

Cuban, L. (1999b). The technology puzzle. Education Week, 18(43), 68-69.

Cuban, L. (2000). Is spending money on technology worth it? Education Week, 19(24), 42.

Cuban, L. (2006, June). Centennial Reflections: Getting past futile pedagogical wars. Phi Delta Kappan, 793-795.

Cuban, L., Kirkpatrick, H., \& Peck, C. (2001). High access and low use of technologies in high school classrooms: Explaining an apparent paradox. American Educational Research Journal, 38, 813-834.

Culp, K. M., Honey, M., \& Mandinach, E. (2005). A retrospective on twenty years of education technology policy. Journal of Educational Computing Research, 32, 279-307.

Cummings, D., \& Buzzard, C. (2002, November/December). Technology, students, and faculty...how to make it happen! Techniques, 30-33.

Delialioglu, O., \& Yildirim, Z. (2008). Design and development of a technology enhanced hybrid instruction based on MOLTA model: Its effectiveness in comparison to traditional instruction. Computers \& Education, 51, 474-483.

Dictionary.com. Hardware. http://dictionary.reference.com/browse/hardware. Retrieved: December 10, 2010.

Dictionary.com. Internet. http://dictionary.reference.com/browse/Internet. Retrieved: December 10, 2010. 
Dictionary.com. Software. http://dictionary.reference.com/browse/software. Retrieved: December 10, 2010.

Donaldson, J. A. (2009). Definition to Practice: Translating the definition into a standards-based IT program. TechTrends, 53(5), 29-33.

Doolittle, P. E., \& Hicks, D. (2003). Constructivism as a theoretical foundation for the use of technology in social studies. Theory and Research in Social Education, 31, 71-103.

Englert, C. S., Manalo, M., and Zhao, Y. (2004). I can do it better on the computer: The effects of technology-enabled scaffolding on young writers' composition. Journal of Special Education Technology, 19, 5-21.

Erdoğan, M., Kursun, E., Tan Sisman, G., Saltan, F., Gök, A., \& Yildiz, I. (2010). A qualitative study on classroom management and classroom discipline problems, reasons, and solutions: A case of information technologies class. Educational Sciences: Theory and Practice, 10, 881-891.

Ertmer, P. A., \& Ottenbreit-Leftwich, A. T. (2010). Teacher technology change: How knowledge, confidence, beliefs, and culture intersect. Journal of Research on Technology in Education, 42, 255-284.

Fazarinc, Z., Divjak, S., Korošec, D., Holobar, A., Divjak, M., \& Zazula, D. (2003). Quest for effective use of computer technology in education: From natural sciences to medicine. Using Computer Technologies in Education and Training, $116-131$. 
Ferneding, K. A. (2003). Alternative visions: Questioning technocentrism. Questioning Technology: Electronic Technologies and Educational Reform, 41-87. Retrieved December 1, 2010, from Education Research Complete database.

Fletcher, D. (2006). Technology integration: Do they or don't they? A self-report survey from preK through $5^{\text {th }}$ grade professional educators. Association for the Advancement of Computing in Education Journal, 14, 207-219.

Frye, N. E., \& Dornisch, M. M. (2007-2008). Teacher technology use and student evaluations: The moderating role of content area. Journal of Educational Technology Systems, 36, 305-317.

Gall, M., \& Breeze, N. (2008). Music and eJay: An opportunity for creative collaboration in the classroom. International Journal of Educational Research, 47, 27-40.

Gentry, J. (2008). E-publishing's impact on learning in an inclusive sixth grade social studies classroom. Journal of Interactive Learning Research, 19, 455-467.

Gimbert, B., \& Cristol, D. (2004). Teaching curriculum with technology: Enhancing children's technological competence during early childhood. Early Childhood Education Journal, 31, 207-216.

Glazer, E. M., Hannafin, M. J., Polly, D., \& Rich, P. (2009). Factors and interactions influencing technology integration during situated professional development in an elementary school. Computers in the Schools, 26, 21-39.

Glazer, E., Hannafin, M. J., \& Song, L. (2005). Promoting technology integration through collaborative apprenticeship. Educational Technology Research \& Development, 53(4), 57-67. 
Gordan, J. P., \& Still, K. L. (2007). Becoming a techno-teacher: Deal me in. Ohio Journal of English Language Arts, 47, 20-27.

Groff, J., \& Mouza, C. (2008). A framework for addressing challenges to classroom technology use. Association for the Advancement of Computing in Education Journal, 16, 21-46.

Gülbahar, Y. (2008). Improving the technology integration skills of prospective teachers through practice: A case study. The Turkish Online Journal of Educational Technology, 7, 71-81.

Guo, R. X., Dobson, T., \& Petrina, S. (2008). Digital natives, digital immigrants: An analysis of age and ICT competency in teacher education. Journal of Educational Computing Research, 38, 235-254.

Häkkinen, P. (2002). Challenges for design of computer-based learning environments. British Journal of Educational Technology, 33, 461-469.

Harris, J., Mishra, P., \& Koehler, M. (2009). Teachers' technological pedagogical content knowledge and learning activity types: Curriculum-based technology integration reframed. Journal of Research on Technology in Education, 41, 393-416.

Hermans, R., Tondeur, J., van Braak, J., \& Valcke, M. (2008). The impact of primary school teachers' educational beliefs on the classroom use of computers. Computers \& Education, 51, 1499-1509.

Hixon, E., \& Buckenmeyer, J. (2009). Revisiting technology integration in schools: Implications for professional development. Computers in the Schools, 26, 130146. 
Hlynka, D., \& Jacobsen, M. (2009). What is educational technology, anyway? A commentary on the new AECT definition of the field. Canadian Journal of Learning and Technology, 35(2), 9.

Hopson, M. H., Simms, R. L., \& Knezek, G. A. (2001-2002). Using a technologyenriched environment to improve higher-order thinking skills. Journal of Research on Technology in Education, 34, 109-119.

Januszewski, A. (2005). Definition and Terminology Committee. Tech Trends, 50, 10.

Järvelä, S., Veermans, M., \& Leinonen, P. (2008). Investigating student engagement in computer-supported inquiry: A process-oriented analysis. Social Psychology of Education: An International Journal, 11, 299-322.

Joshi, A., Pan, A., Murakami, M., \& Narayanan, S. (2010). Role of computers in educating young children: U.S. and Japanese teachers' perspectives. Computers in the Schools, 27, 5-19.

Kagan, D. M. (1992). Implications of research on teacher belief. Educational Psychologist, 27, 65-90.

Kazanci, Z., \& Okan, Z. (2009). Evaluating English language teaching software for kids: Education or entertainment or both? The Turkish Online Journal of Educational Technology, 8(3), 30-38.

Karchmer-Klein, R. (2007). Audience awareness and internet publishing: A qualitative analysis of factors influencing how fourth graders write electronic text. Action in Teacher Education, 29(2), 39-50. 
Ke, F. (2008). Computer games application within alternative classroom goal structures: cognitive, metacognitive, and affective evaluation. Educational Technology Research \& Development, 56, 539-556.

Keengwe, J. (2007). Faculty integration of technology into instruction and students' perceptions of computer technology to improve student learning. Journal of Information Technology Education, 6, 169-180.

Keengwe, J., \& Anyanwu, L. O. (2007). Computer technology-infused learning enhancement. Journal of Science Education and Technology, 16, 387-393.

Keengwe, J., Onchwari, G., \& Wachira, P. (2008a). Computer technology integration and student learning: Barriers and promise. Journal of Science Education and Technology, 17, 560-565.

Keengwe, J., Onchwari, G., \& Wachira, P. (2008b). The use of computer tools to support meaningful learning. Association for the Advancement of Computing in Education Journal, 16, 77-92.

Klieger, A., Ben-Hur, Y., \& Bar-Yossef, N. (2010). Integrating laptop computers into classroom: Attitudes, needs, and professional development of science teachers- a case study. Journal of Science Education and Technology, 19, 187-198.

Kromhout, O. M., \& Butzin, S. M. (1993). Integrating computers into the elementary school curriculum: An evaluation of nine Project CHILD model schools. Journal of Research on Computing in Education, 26, 55-69.

Kurt, S. (2010). Technology use in elementary education in Turkey: A case study. New Horizons in Education, 58, 65-76. 
Labbo, L. D. (2007). Living in the promised land...or can old and new literacies live happily ever after in the classroom? College Reading Association Yearbook, 28, 20-30.

Lee, H. J. (2004-2005). Developing a professional development program model based on teacher's needs. The Professional Educator, 27, 39-49.

Levin, T., \& Wadmany, R. (2008). Teachers' views on factors affecting effective integration of information technology in the classroom: Developmental scenery. Journal of Technology and Teacher Education, 16, 233-263.

Lim, C. P., \& Chai, C. S. (2008). Teachers' pedagogical beliefs and their planning and conduct of computer-mediated classroom lessons. British Journal of Educational Technology, 39, 807-828.

Lin, C. Y. (2008). Beliefs about using technology in the mathematics classroom: Interviews with pre-service elementary teachers. Eurasia Journal of Mathematics, Science, \& Technology Education, 4, 135-142.

Loveless, T. (1996). Why aren't computers used more in schools? Educational Policy, 10, 448-467.

Lunenberg, F. C. (1998). Constructivism and technology: Instructional designs for successful education reform. Journal of Instructional Psychology, 25, 75-81.

MacBride, R., \& Luehmann, A. L. (2008). Capitalizing on emerging technologies: A case study of classroom blogging. School Science and Mathematics, 108, 173-183.

Mainka, C. (2007). Putting staff first in staff development for the effective use of technology in teaching. British Journal of Educational Technology, 38, 158-160. 
Mautone, J. A., DuPaul, G. J., \& Jitendra, A. K. (2005). The effects of computer-assisted instruction on the mathematics performance and classroom behavior of children with ADHD. Journal of Attention Disorders, 9, 301-312.

Mavrou, K., Lewis, A., \& Douglas, G. (2010). Researching computer-based collaborative learning in inclusive classrooms in Cyprus: The role of the computer in pupils' interaction. British Journal of Educational Technology, 41, 486-501.

Maynard, R. (2010). Computers and young children. Canadian Children, 35, 15-18.

McKenna, M. C., Reinking, D., Labbo, L. D., \& Kieffer, R. D. (1999). The electronic transformation of literacy and its implications for the struggling reader. Reading \& Writing Quarterly, 15, 111-126.

Milliron, M. D., \& Miles, C. L. (1999). Aha! The Internet changes nothing. Supplement Technology, 11(18), 3-5.

Mokhtari, K., Kymes, A., \& Edwards, P. (2008). Assessing the new literacies of online reading comprehension: An informative interview with W. Ian O’Byrne, Lisa Zawilinski, J. Greg McVerry, and Donald J. Leu at the University of Connecticut. The Reading Teacher, 62, 354-357.

Mueller, J., Wood, E., Willoughby, T., Ross, C., \& Specht, J. (2008). Identifying discriminating variables between teachers who fully integrate computers and teachers with limited integration. Computers \& Education, 51, 1523-1537.

Neo, M. (2005). Web-enhanced learning: Engaging students in constructivist learning. Campus-Wide Information Systems, 22, 4-14.

Neo, T.-K., \& Neo, M. (2004). Innovation: Engaging students in interactive multimedia learning. Campus-Wide Information Systems, 21, 118-124. 
Okan, Z. (2007, May). Towards a critical theory of educational technology. Paper presented at the International Educational Technology Conference, Nicosia, Turkish Republic of Northern Cyprus.

O’Neil, J. (2000, April). Fads and fireflies: The difficulties of sustaining change. Educational Leadership, 6-9.

Partington, A. (2010). Game literacy, gaming cultures and media education. English Teaching: Practice and Critique, 9, 73-86.

Pasco, B., \& Adcock, P. G. (2007). New rules, new roles: Technology standards and teacher education. Educational Considerations, 34(2), 29-31.

Pascopella, A. (2008). Web tools: The second generation. District Administration, 44(6), 54-58.

Pearman, C. J. (2008). Independent reading of CD-ROM storybooks: Measuring comprehension with oral retellings. Reading Teacher, 61, 594-602.

Peck, C., Cuban, L., \& Kirkpatrick, H. (2002, April). High-tech's high hopes meet student realities. Phi Delta Kappan, 47-54.

Polly, D., \& Hannafin, M. J. (2010). Reexamining technology's role in learner-centered professional development. Education Technology Research \& Development, 58, $557-571$.

Prensky, M. (2001). Digital native, digital immigrants. NCB University Press, 9(5), 1-6.

Prensky, M. (2008, May-June). The courage to change: Guiding teachers to the new paradigm. Educational Technology, 64. 
Razfar, A. (2008). Developing technological literacy: A case study of technology integration in a Latina liberal arts college. Association for the Advancement of Computing in Education Journal, 16, 327-345.

Russell, M., Bebell, D., O’Dwyer, L., \& O’Connor, K. (2003). Examining teacher technology use: Implications for preservice and inservice teacher preparation. Journal of Teacher Education, 54, 297-310.

Ruthven, K., Hennessy, S., \& Deaney, R. (2008). Constructions of dynamic geometry: A study of interpretative flexibility of educational software in classroom practice. Computers \& Education, 51, 297-317.

Salpeter, J. (2008). Make students info literate: There remains a larger challenge for schools- how to develop a new generation of knowledgeable digital citizens who can operate in the unregulated online world. Technology \& Learning, 28(10), 2426.

Scardamalia, M., \& Bereiter, C. (2008). Pedagogical biases in educational technologies. Educational Technology Magazine: The Magazine for Managers of Change in Education, 48(3), 3-11.

Schrand, T. (2008). Tapping into active learning and multiple intelligences with interactive multimedia: A low-threshold classroom approach. College Teaching, 56(2), 78-84.

Scoolis, J. (1999). Infusing your curriculum with technology. Thrust for Educational Leadership, 28(4), 14-16.

Selwyn, N. (2008). Realising the potential of new technology? Assessing the legacy of new labour's ICT agenda 1997-2007. Oxford Review of Education, 34, 701-712. 
Shepherd, C., \& Mullane, A. M. (2010). Managing multimedia mania: Taming the technology beast. Journal of College Teaching \& Learning, 7, 59-70.

Silman, F., \& Gündoğdu, K. (2007, May). Teachers' perceptions of computer use in education in the TRNC schools. Paper presented at the International Educational Technology Conference, Nicosia, Turkish Republic of Northern Cyprus.

Simpson, E., \& Clem, F. A. (2008). Video games in the middle school classroom. Middle School Journal, 39(4), 4-11.

Solhaug, T. (2009). Two configurations for accessing classroom computers: differential impact on students' critical reflections and their empowerment. Journal of Computer Assisted Learning, 25, 411-422.

State of Ohio Board of Education. (2003). Technology Academic Content Standards. Retrieved November 26, 2008, from <http://education.ohio.gov/GD/Templates/Pages/ODE/ ODEDetail.aspx ?page $=3 \&$ TopicRelationID $=1707 \&$ ContentID $=1279 \&$ Content $=8$ 8699>

Steketee, C. (2005). Integrating ICT as an integral teaching and learning tool into preservice teacher training courses. Issues in Educational Research, 15, 101-113.

Tearle, P. (2003). ICT implementation: what makes the difference? British Journal of Educational Technology, 34, 567-583.

Thomas, M. O. J., \& Vela, C. (2003). Computers in the primary classroom: Barriers to effective use. International Group for the Psychology of Mathematics Education, 4, 347-354. 
Tondeur, J., Valcke, M., \& van Braak, J. (2008). A multidimensional approach to determinants of computer use in primary education: teacher and school characteristics. Journal of Computer Assisted Learning, 24, 494-506.

Tondeur, J., Devos, G., Van Houtte, M., van Braak, J., \& Valcke, M. (2009).

Understanding structural and cultural school characteristics in relation to educational change: the case of ICT integration. Educational Studies, 35, 223235.

Tuck, K. (2004, October). Gains and gaps in education technology: An NEA survey of educational technologies in U.S. schools. National Education Association Research Department.

U.S. Department of Education. (2004). Toward a new golden age in American education: How the Internet, the law, and today's students are revolutionizing expectations. National Education Technology Plan 2004.

Valanides, N., \& Angeli, C. (2008). Professional development for computer-enhanced learning: a case study with science teachers. Research in Science \& Technological Education, 26, 3-12.

Van Braak, J., Tondeur, J., \& Valcke, M. (2004). Explaining different types of computer use among primary school teachers. European Journal of Psychology of Education, 19, 407-422.

Viadero, D. (2005). Pressure builds for effective staff training. Education Week, 24(43), $1-21$. 
Waddoups, G. L., Wentworth, N., \& Earle, R. (2004). Principles of technology integration and curriculum development: A faculty design team approach. The Haworth Press, inc.

Wentworth, N., \& Earle, R. (2003). Trends in computer uses as reported in 'Computers in the Schools'. Technology in Education: A Twenty-Year Retrospective. The Haworth Press, inc.

Wright, R. J., \& Lesisko, L. J. (2008, March). Technology infusion in a rural school system: A case study from Pennsylvania. Paper presented at the Annual Meeting of the American Educational Research Association, New York.

Wright, S. W. (1996). Technology integration, user support top faculty wish lists. Community College Week, 9(9), 10.

Yaghi, H. M., \& Ghaith, G. M. (2002). Correlates of computing confidence among teachers in an international setting. Computers in the Schools, 19, 81-94.

Zhao, Y. (2006, May). Are we fixing the wrong things? Educational Leadership, 28-31.

Zhao, Y., Hueyshan Tan, S., \& Mishra, P. (2000-2001). Teaching and learning: Whose computer is it? Journal of Adolescent \& Adult Literacy, 44, 348-354. 


\section{APPENDIX I}

\section{School Culture and Current Use Survey}

Name:

Date:

Please put your name on this survey for the purposes of identifying possible mentor candidates. Only the implementer will see your name in conjunction with your answers. No other people (including administrators or parents) will have access to your individual responses in conjunction with your name.

Special Note: For the purposes of this survey, ICT refers to specific technology used for accessing and disseminating information (i.e. computers, laptops, Internet, production software such as Microsoft Word or Microsoft PowerPoint, e-mail, etc.)

How much pressure do you feel to cover all of the textbook and workbook pages provided to you?

$\begin{array}{ccccccccc}1 & 2 & 3 & 4 & 5 & 6 & 7 & 8 & 9 \\ \text { None } & \text { Little } & & \text { Some } & & \text { Moderate } & & \text { Significant } & \text { Extreme }\end{array}$

What percentage of this pressure would you estimate comes from external sources?

What percentage of this pressure would you estimate comes from internal beliefs?

To what degree do your administrators expect you to utilize ICT in the classroom?

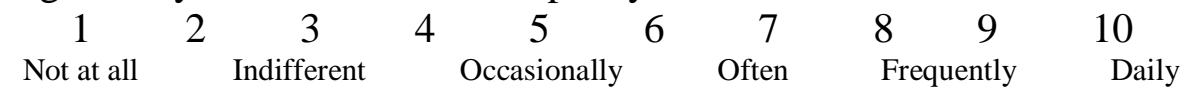

To what degree do your administrators expect you to utilize ICT in the classroom for inquiry learning?

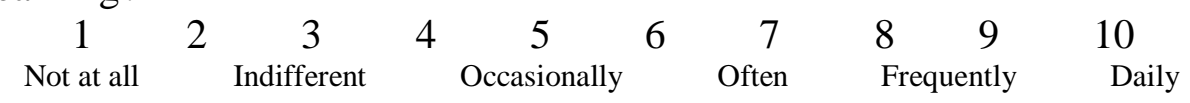

To what degree do you believe that you would have administrative support for using ICT as a catalyst for inquiry learning on a regular, consistent basis?

$$
\begin{array}{cccccccccc}
1 & 2 & 3 & 4 & 5 & 6 & 7 & 8 & 9 & 10 \\
\text { None } & & & & & & & & & \text { Extensive }
\end{array}
$$

To what degree do you believe that you would have parental support for using ICT as a catalyst for inquiry learning on a regular, consistent basis?

$\begin{array}{cccccccccc}1 & 2 & 3 & 4 & 5 & 6 & 7 & 8 & 9 & 10 \\ \text { None } & & & & & & & & & \text { Extensive }\end{array}$

To what degree do you believe that you would have technological support for using ICT as a catalyst for inquiry learning on a regular, consistent basis?

$\begin{array}{cccccccccc}1 & 2 & 3 & 4 & 5 & 6 & 7 & 8 & 9 & 10 \\ \text { None } & & & & & & & & & \text { Extensive }\end{array}$


How often do you utilize ICT for personal reasons?

$$
\begin{array}{cccccccccc}
1 & 2 & 3 & 4 & 5 & 6 & 7 & 8 & 9 & 10 \\
\text { Never } & \text { A Little } & \text { Occasionally } & & \text { Often } & \text { Frequently } & \text { Daily }
\end{array}
$$

How often do you utilize ICT for lesson preparation, identifying or accessing resources, displaying Power Points or other notes to your class, or preparing special activities?

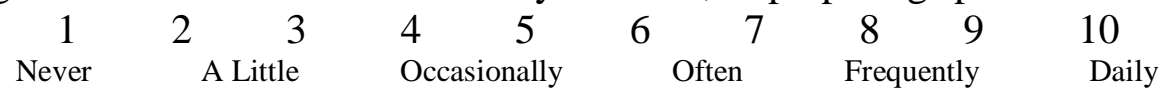

How often do you utilize ICT for professional communication with administrators, colleagues, students, or parents?

$$
\begin{array}{cccccccccc}
1 & 2 & 3 & 4 & 5 & 6 & 7 & 8 & 9 & 10 \\
\text { Never } & \text { A Little } & \text { Occasionally } & & \text { Often } & \text { Frequently } & \text { Daily }
\end{array}
$$

How would you rate your access to ICT for personal and professional use?

$$
\begin{array}{ccccccccc}
1 & 2 & 3 & 4 & 5 & 6 & 7 & 8 & 9 \\
\text { No access } & \text { Occasional access } & & \text { Some access } & \text { Easy access } & & \text { Ongoing access }
\end{array}
$$

How often do your students utilize ICT in the classroom for producing products (i.e. typing reports, PowerPoint presentations, making brochures, etc.)?

$$
\begin{array}{ccccccccc}
1 & 2 & 3 & 4 & 5 & 6 & 7 & 8 & 9 \\
\text { Never } & \text { A Little } & \text { Occasionally } & & \text { Often } & \text { Frequently } & \text { Daily }
\end{array}
$$

How often do your students utilize ICT in the classroom for inquiry learning activities and learning new concepts?

$$
\begin{array}{cccccccccc}
1 & 2 & 3 & 4 & 5 & 6 & 7 & 8 & 9 & 10 \\
\text { Never } & \text { A Little } & & \text { Occasionally } & & \text { Often } & \text { Frequently } & \text { Daily }
\end{array}
$$

How would you rate your access to ICT for instructional and student use in the classroom?

$$
\begin{array}{cccccccccc}
1 & 2 & 3 & 4 & 5 & 6 & 7 & 8 & 9 & 10 \\
\text { No access } & & \text { Occasional access } & & \text { Some access } & & \text { Easy access } & & \text { Ongoing access }
\end{array}
$$

What level of outside support do you have for utilizing ICT in the classroom?

$$
\begin{array}{cccccccccc}
1 & 2 & 3 & 4 & 5 & 6 & 7 & 8 & 9 & 10 \\
\text { None } & & & & & & & & & \text { Extensive }
\end{array}
$$




\section{APPENDIX II}

\section{Belief Meets Action}

This survey is for your personal use in order to help you identify your internal beliefs about pedagogy and the pedagogical style seen most frequently in your classroom actions and activities.

For each statement below indicate your level of agreement based on the scale provided.

1. I believe it is important to consider student interests when determining topics of study in the classroom.
Strongly Disagree
3
Disagree
$5 \begin{array}{r}6 \\ \text { Neutral }\end{array}$
$7 \begin{array}{r}8 \\ \text { Agree }\end{array}$
$9 \quad 10$
Strongly Agree

2. The majority of class time should be spent with the teacher presenting information and students taking notes or answering review questions.
$\begin{array}{cc}1 & 2 \\ \text { Strongly Disagree }\end{array}$
$\begin{array}{lr}3 & 4 \\ & \text { Disagree }\end{array}$
$5 \quad 6$
$7 \quad 8 \quad 9$
Agree Strongly Agree

3. My objectives frequently require the use of higher order thinking skills.
$\begin{array}{cr}1 & 2 \\ \text { Strongly Disagree }\end{array}$
$\begin{array}{rr}3 & 4 \\ \text { Disagree } & \end{array}$
$5 \quad 6$
$\begin{array}{rr}7 & 8 \\ \text { Agree }\end{array}$
$\begin{array}{ll}9 & 10 \\ \text { Strongly Agree }\end{array}$

4. The majority of questions on assignments, tests, and quizzes assess student knowledge of facts and definitions.
$\begin{array}{cr}1 & 2 \\ \text { Strongly Disagree }\end{array}$
$\begin{array}{lr}3 & 4 \\ & \text { Disagree }\end{array}$
$5 \quad 6$
$7 \begin{array}{r}8 \\ \text { Agree }\end{array}$
10
Strongly Agree

5. I encourage my students to develop deep understandings of topics studied.

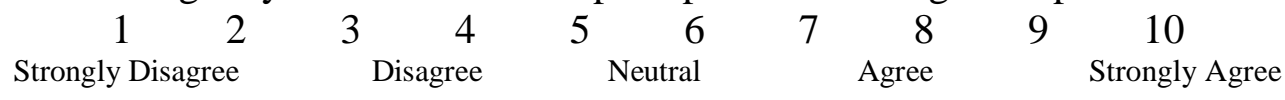

6. The majority of class time in my classroom is spent with me presenting information and students taking notes or answering review questions.

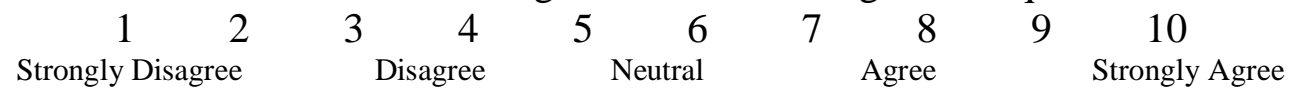

7. I frequently plan lessons that promote inquiry learning and require students to be responsible for their own learning.

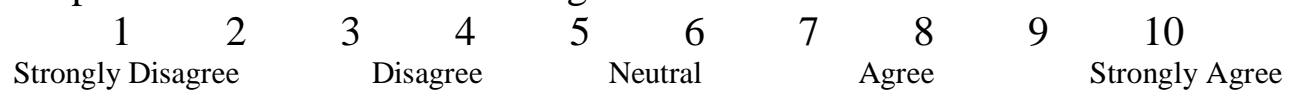

8. Most topics of study in my classroom are determined by the material presented in the textbooks provided to me.

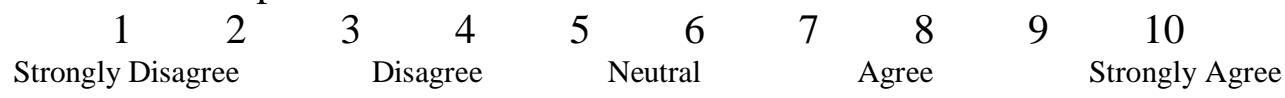

9. The majority of class time in my classroom is spent on student-driven discussions and investigations.

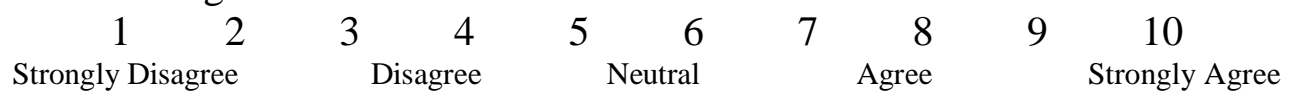


10. The majority of students attend school and complete assigned tasks because of the threat of consequences or poor grades for incomplete work.

\begin{tabular}{|c|c|c|}
\hline \multirow{2}{*}{\multicolumn{2}{|c|}{$\begin{array}{cr}1 & 2 \\
\text { Strongly Disagree }\end{array}$}} & 3 \\
\hline & & agree \\
\hline
\end{tabular}

11. Students in my classroom frequently work in groups to solve authentic problems.

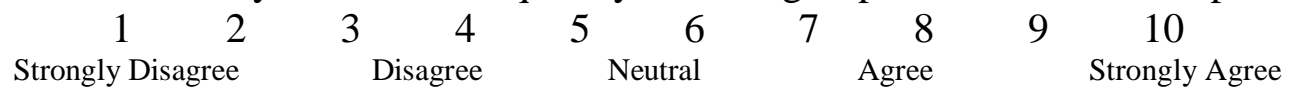

12. Interdisciplinary activities require more preparation time and scheduling adjustments than they are worth.

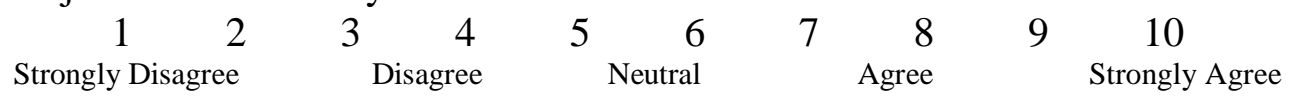

13. My role as a teacher is to provide students with authentic questions or problems and guide them in their quest for answers and determination of the best way to present their understandings of the concepts studied.

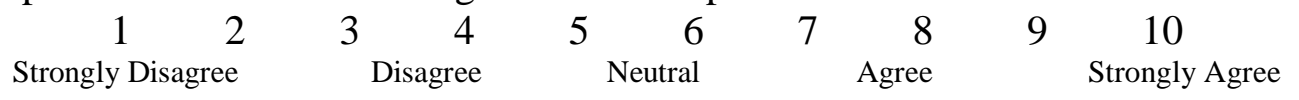

14. The majority of activities completed in my classroom are done individually.

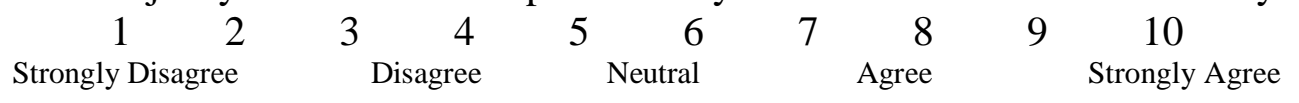

15. The majority of students have an innate curiosity and desire to learn new things.
12
$\begin{array}{rr}3 & 4 \\ \text { Disagree }\end{array}$
6
Neutral
78
$9 \quad 10$
Strongly Disagree $\quad$ Disagree Neutral Agree Strongly Agree

16. My role as a teacher is to present the topics required by my curriculum and assess student knowledge of the concepts presented.

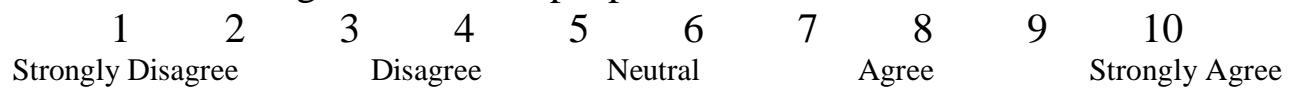

17. I frequently provide opportunities for students to gain a deep understanding of topics covered.

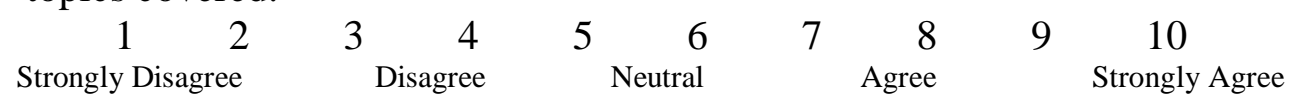

How much pressure do you feel to cover all of the textbook and workbook pages provided to you?

$$
\begin{array}{ccccccccc}
1 & 2 & 3 & 4 & 5 & 6 & 7 & 8 & 9 \\
\text { None } & \text { Little } & & \text { Some } & & \text { Moderate } & & \text { Significant } & \text { Extreme }
\end{array}
$$

What percentage of this pressure would you estimate comes from external sources?

What percentage of this pressure would you estimate comes from internal beliefs?

How often do you utilize forms of assessment other than workbook pages, chapter and section reviews, or tests and quizzes provided with your textbook?

$$
\begin{array}{cccccccccc}
1 & 2 & 3 & 4 & 5 & 6 & 7 & 8 & 9 & 10 \\
\text { Never } & \text { A Little } & \text { Occasionally } & & \text { Often } & \text { Frequently } & \text { Daily }
\end{array}
$$

